\section{O uso de sig no inventário de árvores no Campus do Instituto Politécnico de Bragança, Portugal}

Carolina Ramalho Brito*

João Paulo Miranda de Castro**

Kelly Oliveira Barros ${ }^{* * *}$

André Luiz Lopes de Faria ${ }^{* * *}$

*Bacharel e Licenciada em Geografia, Universidade Federal de Viçosa (UFV). Mestranda em Solos e Nutrição de Plantas da UFV. **Professor do Departamento de Engenharia Florestal do Instituto Politécnico de Bragança (IPB).

***Bacharel em Geografia, Mestre e Doutoranda em Ciência Florestal na UFV.

****Professor do Departamento de Geografia da UFV.

\section{Palavras-chave:}

Sistemas de Informações Geográficas; Espécie arbórea; Arborização urbana.

\footnotetext{
Abstract: This article aimed to realize a forest inventory with the incorporation of Geographic Information Systems. The study was carried out at the Santa Apolonia campus, Polytechnic Institute of Bragança, Bragança (IPB), Portugal. In addition of the inventory, it was realized recommendations and the spatial distribution of the individuals surveyed, and individually, the most common species. The use of Geographic Information Systems was a key tool to support the urban inventory accomplished. From the characteristics and spatial distribution can be realized the need to prepare an arborization plan for the area in the campus in study. Thus, measures related to the management of the species can be efficiently applied.
}

\section{Key-words:}

Geographic Information System; Tree species; Urban arborization. 


\section{Introdução}

A busca por uma relação mais equilibrada entre o homem e o ambiente natural tem sido uma constante nos dias atuais. $O$ intenso crescimento urbano fez com que as áreas naturais perdessem espaços significativos. Neste contexto, muitas características que mantinham o equilíbrio entre os diversos componentes do meio físico, biótico e antrópico foram perdidos, fazendo com que a qualidade de vida fosse comprometida, como por exemplo, lançamento de efluentes atmosféricos e líquidos, construção em áreas de risco, impermeabilização do solo, perda da cobertura vegetal, dentre outros.

A vegetação urbana desempenha diversas funções de grande relevância. As árvores, por suas características naturais, proporcionam muitas vantagens ao homem que vive na cidade, sob vários aspectos, dentre eles: proporcionar bem estar psicológico; melhor efeito estético; sombra para os pedestres e veículos; protegem e direcionam o vento; amortecem o som, amenizam a poluição sonora; minimizam o impacto da água de chuva e seu escorrimento superficial; melhoram a qualidade do ar; preservam a fauna silvestre (PIVETTA, 2002).

Observa-se na paisagem a imposição de uma leitura integradora, traduzida numa visão multidisciplinar da realidade urbana, em que os espaços verdes se organizam em torno de uma estrutura verde urbana, que constitui um conjunto hierárquico e coerente, capaz de salvaguardar elementos territorialmente relevantes e de contrariar os efeitos nefastos da urbanização, através da promoção dos múltiplos benefícios dos espaços verdes (CARVALHO, 2008).

As paisagens podem ser consideradas espaços regidos por um sistema de evolução antrópica, apoiado na história, na economia, na sociologia e na estética; essa ação antrópica é um elemento entre outros existentes na combinação ecológica, não se devendo separar o aspecto ecológico do contexto socioeconômico (BERTRAND, 2004).

Para tanto, torna-se necessário o conhecimento do patrimônio arbóreo, que pode ser obtido por meio de inventário, recurso que se constitui em uma ferramenta fundamental para a obtenção de informações precisas acerca da população arbórea (LIMA NETO et al, 2010).

Com 0 avanço tecnológico, a "paisagem natural" vem sendo substituída pela "paisagem urbana" e pela "paisagem rural". As drásticas mudanças na "paisagem natural" têm ocasionado problemas ecológicos e sociais (MAGRO, 1997). Desse modo, a necessidade de criação, preservação e promoção dos espaços verdes e sua inserção numa estrutura ecológica constituem peças vitais de gestão ambiental e planejamento estratégico do lugar, ganhando especial importância a dotação de instrumentos regulamentares e orientadores que permitam o prosseguimento desses objetivos e contribuam para melhoria da qualidade de vida da população.

A realização de um inventário é o meio mais seguro de compreender o patrimônio arbóreo de uma localidade. Tal levantamento é fundamental para o planejamento e manejo da arborização, fornecendo informações sobre a necessidade de poda, tratamentos fitossanitários ou remoção e plantios, bem como define prioridades de intervenções. A debilidade e a complexidade desse sistema a ser administrado exigem um planejamento cauteloso, com os objetivos de aprimorar as funções da arborização e de minimizar custos (MENEGUETTI, 2003; VITÓRIA et al., 2010).

Uma importante ferramenta que auxilia o monitoramento e o mapeamento para levantamento de um inventário arbóreo é o Sistema de Informações Geográficas (SIG) (LIMA NETO, 2011). Este tem potencial de aplicação como ferramenta para oferecer suporte à arborização na descrição de dados espaciais a partir da realidade, na perspectiva de facilitar o gerenciamento e corrigir os

Geografia Ensino \& Pesquisa, v. 16, n. 3 p. $157-178$, set./dez. 2012

0 uso de sig no inventário de árvores no Campus do Instituto Politécnico de Bragança, Portugal eventuais problemas. Para isso, eles permitem a entrada, tratamento, monitoramento e atualização de dados geográficos, sobre uma base de dados georreferenciada. A partir da confecção desta base, o SIG tem múltiplos usos, como por exemplo, mapeamento de áreas de risco, confecção de mapas temáticos, dentre outras aplicações.

Neste sentido foi realizado um inventário dos indivíduos arbóreos do Instituto Politécnico de Bragança, Bragança, Portugal, com a incorporação dos Sistemas de Informações Geográficas. 


\section{Material e métodos}

O município de Bragança situa-se na Península Ibérica, localizado nas coordenadas geográficas $41^{\circ} 48^{\prime} \mathrm{N} 6^{\circ} 50^{\prime} \mathrm{W}$ (Figura 1) e é limitada a norte e a leste pela Espanha (CÂMARA MUNICIPAL DE BRAGANÇA, 2010).

Figura 1- Localização do município de Bragança, Portugal

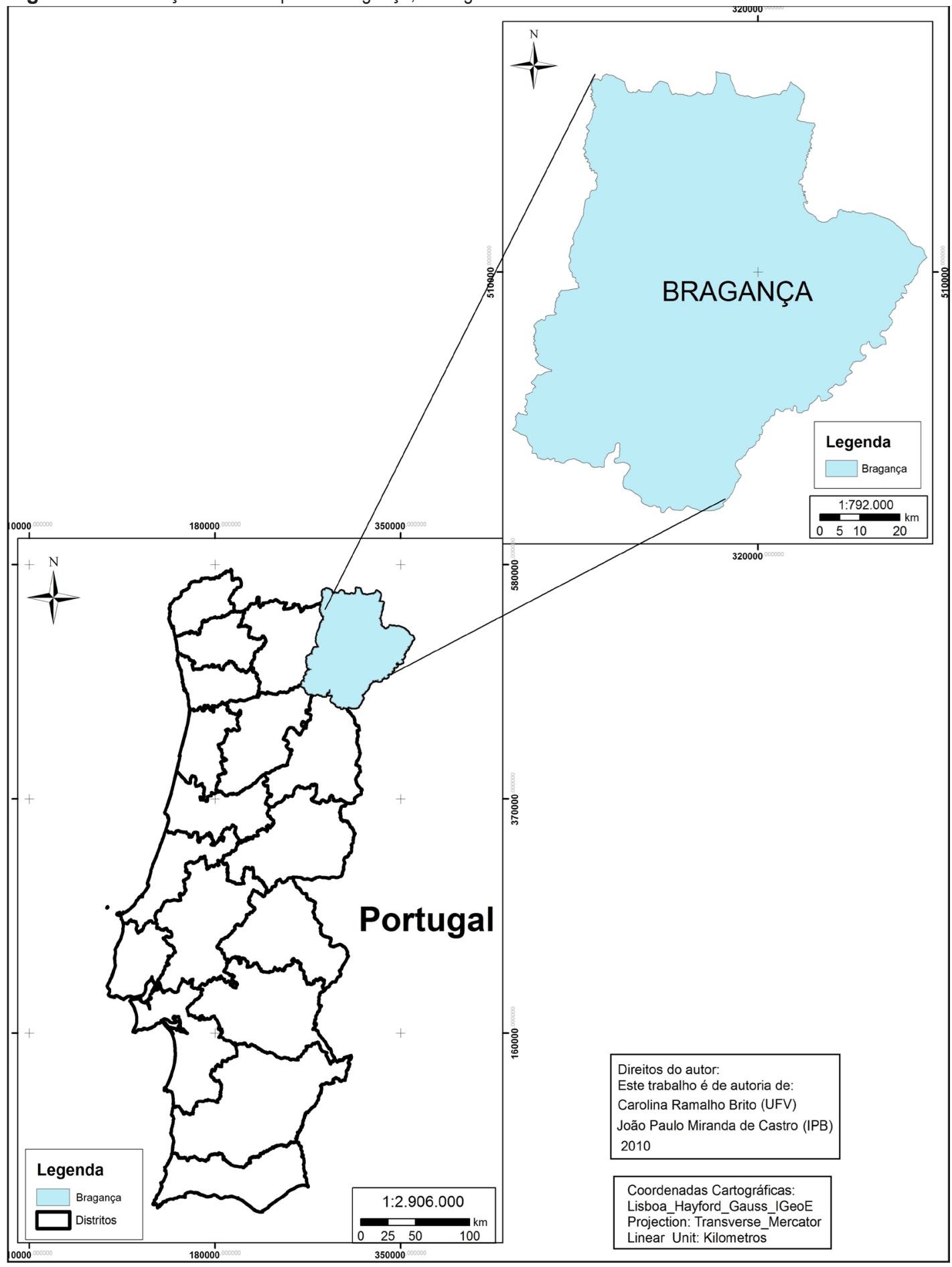

Fonte: CÂMARA MUNICIAPL DE BRAGANÇA, 2010.

Geografia Ensino \& Pesquisa, v. 16, n.3 p. $157-178$, set./dez. 2012

O Instituto Politécnico de Bragança (Figura 2) é uma instituição pública de ensino superior que possui quatro escolas superiores em Bragança e uma em Mirandela. A área de estudo corresponde ao campus Santa Apolónia, localizado em Bragança (IPB, 2010).

Brito, C.R.; Castro, J.P.M. de; Barros, K. O.; Faria, A.L.L. de. 
Figura 2- Imagem aérea do Campus do Instituto Politécnico de Bragança, Santa Apolónia, Bragança/Portugal. Ano: 2006

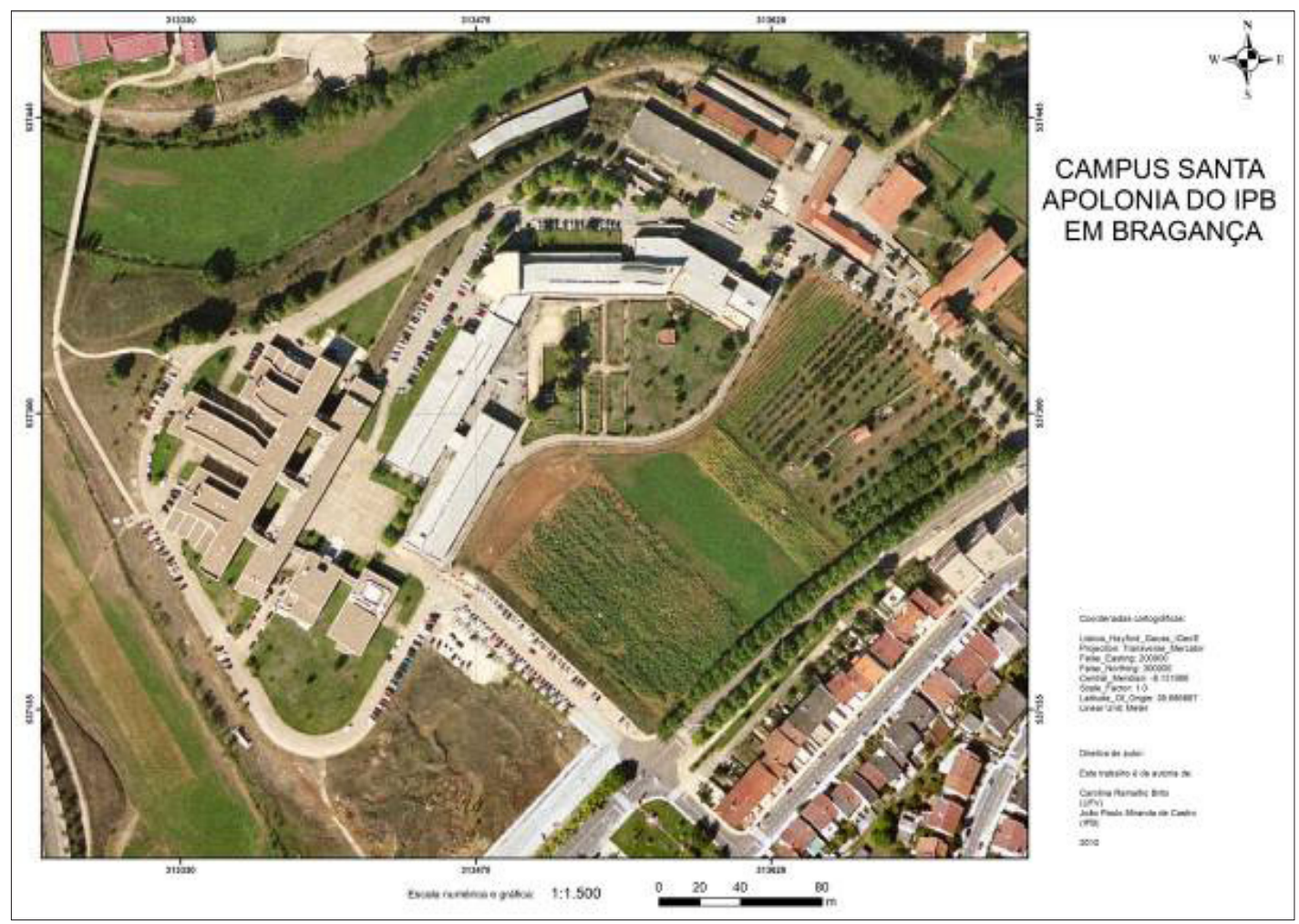

Fonte: CÂMARA MUNICIPAL DE BRAGANÇA, 2010.

O Parque arbóreo do campus do IPB, Santa Apolónia, conta com árvores ripícolas e árvores de comportimentação de parcelas com pastagem permanente. Ressalta-se que os pomares não foram considerados neste inventário.

No que se refere a parte arbórea do campus Santa Apolónia foram detectadas algumas falhas de manutenção e mesmo algumas situações de vandalismo. Ainda assim, pode-se considerar que este patrimônio arbóreo tem grande potencial para evoluir favoravelmente e contribuir para 0 melhoramento da qualidade de vida das pessoas que frequentam o campus.

\section{Procedimentos metodológicos}

Foi realizada a localização, identificação e avaliação das árvores no campus Santa Apolónia. Todos os indivíduos arbóreos inventariados foram espacializados assim como também, em caráter individual, algumas espécies de maior ocorrência no campus Santa Apolónia. Em seguida, os dados foram organizados em uma base de dados que permite gerir e consultar a informação.

Por fim, da apreciação técnica efetuada no campo foram elaborados gráficos e tabelas que realçam os aspectos considerados relevantes. Ressalta-se que nem todos os indivíduos arbóreos foram considerados no inventário. As árvores ripícolas e aquelas de compartimentação de parcelas com pastagem permanente e os pomares foram desconsideradas. As espécies ripícolas não foram inventariadas porque estão no estado selvagem, sem grandes intervenções regulares.

Geografia Ensino \& Pesquisa, v. 16, n.3 p. 157 - 178, set./dez. 2012

O uso de sig no inventário de árvores no Campus do Instituto Politécnico de Bragança, Portugal

\section{Parâmetros}

Os parâmetros avaliados no campo foram - Tipo de espécie, Idade, Diâmetro da copa da árvore, Altura da Copa, Diâmetro à altura do peito (DAP), Associação, Tipo de pavimento, Irrigação, Fatores Limitantes, Sanidade da árvore e as Intervenções Recomendadas.

A idade da árvore foi classificada qualitativamente em Juvenil, Adulta, Senescente, Morta presente e Sem árvore. Foi considerado Sem árvore os espaços onde outrora teve uma árvore ou 
que tem o espaço para se colocar uma. Quando uma árvore já está formada, já tem a casca enrugada (casca suberificada), o seu crescimento em altura estagnou, e já atingiu maturidade sexual, então poderemos dizer que é adulta, caso contrário, é juvenil, período no qual são realizadas as podas de formação. Quando uma árvore começa a ter sintomas como ramos secos e partidos, feridas no tronco, cavidades, etc., então está a atingir a senescência.

Para medir o DAP foi utilizado a sutra, enquanto que para a altura da copa foi utilizado o hipsômetro. No que se refere à Associação, este parâmetro indica a distribuição no espaço geográfico das espécies. Neste sentido, esta distribuição pode ser classificada como Alameda de árvores - considerada diversas árvores em sequência num alinhamento; Bosquete - algumas árvores reunidas espaçadas; Outro alinhamento - pode ser um talude de proteção e estacionamento. A opção Verificar é utilizada quando deve se fazer uma nova inspecção num curto período de tempo, onde a situação do indivíduo se encontra com problemas e precisa de ajustes.

O Tipo de pavimento refere-se ao local que se encontra o indivíduo arbóreo, classificado em - Asfalto, Calçada, Cimento, Ervado, Relvado, Terra, Outro e Verificar. O Ervado é um local onde possui vegetação mais consistente, como por exemplo uma mata. Já o Relvado é um terreno coberto de grama, ou seja, gramado, como por exemplo, um campo de futebol.

No que tange à irrigação, foi verificada qual tipo de irrigação estava sendo utilizado. Os possíveis tipos de irrigação considerados foram: Sem irrigação, Irrigação por aspersão, Irrigação por gotejamento, Irrigação superficial, Não aplicável e Verificar.

Os Fatores Limitantes indicam o que está inviabilizando o crescimento do indivíduo. Estes foram divididos em seções - raiz, copa e global e podem ser observados na Tabela 1. Foi considerado uma classe de 0 a 4 , de acordo com a necessidade de intervenção, no qual a classe 4 é aquela de maior necessidade de intervenção.

Tabela 1- Fatores limitantes da raiz, copa e global

\begin{tabular}{|l|l|}
\hline $\begin{array}{l}\text { Seção da } \\
\text { árvore }\end{array}$ & Fatores limitantes \\
\hline Raiz & $\begin{array}{l}\text { Nenhum, Outros fatores, Vários fatores, Caldeiras dimensões, Compactação, Edifícios, Parking, } \\
\text { Estradas, Idade, Obras na vizinhança, Lojas, Outras árvores, Passeios, Podas anteriores, Rede de } \\
\text { gás, Rede de esgoto, Rede elétrica, Rega }\end{array}$ \\
\hline Copa & $\begin{array}{l}\text { Nenhum, Outros fatores, Edifícios, Parking, Estradas, Idade, Obras na vizinhança, Lojas, Outras } \\
\text { árvores, Passeios, Podas anteriores, Verificar }\end{array}$ \\
\hline Global & $\begin{array}{l}\text { Nenhuma, Outros fatores, Vários fatores, Caldeira dimensões, Compactação, Edifícios, Parking, } \\
\text { Estradas, Idade, Obras na vizinhança, Lojas, Outras árvores, Passeios, Podas anteriores, Rede de } \\
\text { gás, Rede de esgoto, Rede elétrica, Rega }\end{array}$ \\
\hline
\end{tabular}

A avaliação da sanidade dos indivíduos arbóreos é um fator importante para verificar quais sintomas estão os impedindo de ter um crescimento saudável. Este parâmetro também colabora na identificação dos cuidados que devem ser adotados e quais medidas devem ser tomadas em prol da árvore. A saúde da árvore foi avaliada também em seções - copa, tronco e folhas (Tabela 2).

Tabela 2- Fatores limitantes da raiz, copa e global

\begin{tabular}{|l|l|}
\hline $\begin{array}{l}\text { Seção da } \\
\text { árvore }\end{array}$ & Fatores limitantes \\
\hline Copa & $\begin{array}{l}\text { Normal padrão, Decoloração, Desfolha, Colapso, Doença foliar, Vários Sintomas, Vandalismo, } \\
\text { Verificar }\end{array}$ \\
\hline Tronco & $\begin{array}{l}\text { Normal padrão, Cancrios, Podridão, Crescimento da codominante, Esferoplastos, Feridas, Fungos } \\
\text { e pragas, Partido, Vários sintomas, Vandalismo, Verificar }\end{array}$ \\
\hline Folhas & $\begin{array}{l}\text { Normal, Descoloração, Desfoliação, Dieback, Doença foliar, Diversos sintomas, Vandalismo, Sem } \\
\text { árvore, Verificar }\end{array}$ \\
\hline
\end{tabular}

Geografia Ensino \& Pesquisa, v. 16, n.3 p. 157 - 178, set./dez. 2012

Brito, C.R.; Castro, J.P.M. de; Barros, K. O.; Faria, A.L.L. de. 
As Intervenções recomendadas são necessárias para a melhoria da qualidade das especies arbóreas. As possíveis intervenções apontadas foram: Sem necessidade, Nova inspeção, Eliminar a árvore, Diversas ações, Abate, Ajuste tutor, Colocar tutor, Remover tutor, Alargar caldeira, Fertilização, Limpar cavidade, Limpeza de colo, Nova plantação, Tratamento de planta. Ressalta-se que o tutor corresponde a uma haste qualquer que vai direcionar o crescimento da muda.

Além disso, foi considerado um campo com Podas para avaliar que tipo de poda um individuo arbóreo necessita. Por exemplo, uma poda mal feita implicará numa má conformidade dos ramos. Os tipos de Poda são Sem necessidade, Formação, Ramos ladrões, Mal conformados, Secos e Partidos, Tocos, Acerto de podas e Verificar.

Aidentificação e avaliação de cadaárvore foi feita através do método VTA(Visual TreeAssesment) (CLARK e MATHENY, 1993). O "Visual Tree Assessment (VTA)" é um padrão de diagnóstico e avaliação duma árvore urbana que foi inicialmente proposto por Clark e Matheny, 1993. Este método é muito versátil e bem divulgado (RODRIGUES, 2008a, RODRIGUES, 2008b). É normalmente estipulada uma pontuação no diagnóstico de 0 a 4, segundo o Regulamento (CEE) n. ${ }^{0}$ 1696/87. Cada árvore avaliada com o VTA terá uma "Classe de Estrago" encontrada com base na média das pontuações sobre os vários parâmetros, tais como as condições de sanidade do sistema radicular, tronco, ramos principais, ramos secundários, folha e copa. As adaptações locais do método basearam-se em trabalhos executados para a mesma região, também empregadas em estudos na região da Vila Real e Porto, em Portugal (MARTINS et al, 2003). É um sistema de classificação padrão de árvores, especialmente concebidos para as árvores e arbustos ornamentais. É considerado um sistema interessante para se atribuir um valor a uma determinada espécie arbórea (SARMIENTO, 2005).

Os dados levantados dividem-se em dados administrativos - inspetor, data da primeira observação, data de verificação, Zona, Rua, número incremental de cada árvore, coordenadas $\mathrm{Xe}$ Y (UTM); do local - local, forma de associação, pavimento, condições do pavimento, singularidade da árvore ou interesse especial, tipo de rega, forma da caldeira, condições da caldeira, dimensões da caldeira; da árvore - nome científico da árvore, idade qualitativa, número de troncos, DAP, altura da árvore, altura até base da copa, diâmetro da copa; sanidade e factores limitantes - identificação de fatores limitantes e classificação da severidade do fator (de 0 a 4, 0 - não limitante, 4 - muito severo) da raiz, do tronco, das folhas e da copa e logo após são verificadas a sanidade da raiz, do tronco, das folhas e da copa e classificação da severidade do fator (de 0 a 4)); intervenções e podas - é sugerida intervenção ou não: podas, retirada, derrubada, entre outros, assim como também sua prioridade de intervenção (de 0 a 4); e avaliação patrimonial e nova inspeação - informações se foram ou não feitas a avaliação de risco, no caso de árvores com risco de quebra, e a avaliação patrimonial (Norma de Granada). É finalmente sugerida uma data para nova inspeção.

A localização de cada árvore identificada foi feita através do uso do GPS/PDA Trimble.

\section{Gestão da informação}

O conjunto de dados levantados gerou um dicionário de dados. Foi utilizado neste trabalho um aparelho Trimble GeoXT com precisão submétrica após correção diferencial. 0 firmware TerraSync da Trimble permite a criação de dicionários de dados que facilitam e sistematizam a recolha de informação alfanumérica.

O sistema de coordenadas adotado no inventário foi o Gauss (Lisboa IGE), Zona Lisboa (IGE), Datum Lisboa.

Geografia Ensino \& Pesquisa, v. 16, n.3 p. $157-178$, set./dez. 2012

O uso de sig no inventário de árvores no Campus do Instituto Politécnico de Bragança, Portugal
A interface de comunicação do Trimble GeoXT com o computador é efetuada via USB, através do software GPS Pathfinder Office V4.20 que permite também a correção diferencial, a transformação de coordenadas e a exportação dos dados corrigidos para formato Shapefile, entre outros formatos.

Os atributos são as informações alfanuméricas atribuídas no dicionário de dados. O Inspetor e as datas são dados administrativos para se ter um controle de quem coletou os dados, quando foi a data de observação e a data de verificação que é a data da atualização das informações. 
OArcGIS tem a informação necessária e pode se utilizar uma shapefile existente e importar para atualização de campo. Esta opção faz coincidir características e nomes do GIS com características e definições de atributos no dicionário de dados selecionado. É recomendado utilizar esta opção quando pretende atualizar quaisquer dados de atributo ou coletar novas características no campo.

Como cada árvore depois de inventariada pode ser reinspecionada periodicamente, é importante que se faça a gestão do histórico, isto é, a informação registrada dessa árvore em datas anteriores. A última inspeção é classificada como Atual e todas as restantes como Histórico. Portanto, no ArcGIS só será visualizada a informação atual, ficando a histórica para análises.

\section{Procedimentos adotados}

Depois de inventariada cada árvore é preciso agendar novas inspeções. A navegação para cada árvore é também feita com GPS da Trimble. Cada árvore é numerada com base na sua localização, elas possuem quatro dígitos de numeração, ou seja, pode ter no máximo 9999 árvores numa determinada rua. Isto facilita na identificação do bairro, da rua e a sequenciação de cada árvore nessa rua ou avenida.

Para inventariar as árvores, foram utilizados o sistema de endereços de ruas, GPS e fotografias aéreas, identificando cada indivíduo. Em função do volume de informações, foi criado um banco de dados digital, facilitando a organização dos dados e permitindo sua utilização em ambiente de SIG. Os dispositivos móveis, como PDA (Personal digital assistant), que é um assistente pessoal digital, também conhecido como computador de bolso, têm grande potencialidades, pois eles podem integrar o banco de dados, como também o GPS e SIG. Além dos software GPS Pathfinder Office e do hardware TerraSync, que são muito eficientes e possuem ferramentas fáceis de usar, especialmente no dados de campo e coleta de escritório e de transferência. Todas as informações inseridas são salvas em bases de dados que consistem em coleções organizadas de dados para usos múltiplos. Com essa plataforma pode-se importar/exportar arquivos de bancos de dados para SIG de diferentes sistemas (Shapefile, Geodatabase).

Associado à localização tem numerosa informação alfanumérica que é recolhida no campo: nome científico, medições dos principais parâmetros dendrométricos tais como altura, diâmetro de copa, diâmetro do peito da árvore, estado sanitário, carências, detecção de vandalismo e as intervenções que se preconizam com base no estado da árvore além de avaliações de atributos especiais, por exemplo, histórico, paisagístico e ambiental.

A gestão dessa informação era realizada com o Microsoft Access e depois era interligada a um SIG. Contudo, para viabilizar melhor as informações modificou-se os procedimentos para a eliminação de fichas de campo, sendo o preenchimento e localização e navegação tudo feito com PDA. Desse modo, foi desenvolvido aplicações em dois sistemas: TerraSync da Trimble (marca do

GPS) no desenvolvimento de uma aplicação em ArcPad que é o modo de terreno do ArcGIS com o qual mantém uma ligação estreita.

Os softwares que foram utilizados: ArcGis 9.3.1; ArcPad 7.1 para Windows; ArcPad Studio 7.1.0.59U (This application uses Visual Basic $®$ Scripting Edition and JScript $₫$ from Microsoft $\circledast$ Corporation);: GPS Pathfinder Office 4.20 e TerraSync.

\section{Resultados e discussão}

De acordo com os dados coletados foram encontradas 481 indivíduos arbóreos de 39 espécies distintas (Tabela 3).

Pode-se perceber a baixa diversidade no campus IPB, no qual de 481 indivíduos identificaramse apenas 39 espécies. Dentre os indivíduos encontrados destacaram-se as espécies Cupressus Iusitanica, Platanus hispanica e a Catalpa bignonioides. Ressalta-se que a espécie Cupressus

Geografia Ensino \& Pesquisa, v. 16, n.3 p. 157 - 178, set./dez. 2012

Brito, C.R.; Castro, J.P.M. de; Barros, K. O.; Faria, A.L.L. de.

ISSN 2236-4994 163 
lusitanica, aquela de maior expressividade, é uma das mais antigas do campus. Este cipreste português localiza-se em solos rochosos incipientes, justificando a característica rústica desta espécie.

Tabela 3- Espécies encontradas no Campus do Instituto Politécnico de Brangaça, Santa Apolónia, Brangança, Portugal

\begin{tabular}{|c|c|c|c|}
\hline Espécie & Total & Espécies & Total \\
\hline Acacia melanoxylon & 1 & Olea europaea & 3 \\
\hline Acer campestre & 6 & Pinus pinea & 7 \\
\hline Acer hyrcanum & 2 & Platanus hispanica & 63 \\
\hline Acer negundo & 15 & Populus sp. & 1 \\
\hline Acer pseudoplatanus & 36 & Prunus avium & 3 \\
\hline Aesculus hippocastan & 14 & Prunus cerasifera & 1 \\
\hline Betula celtiberica & 5 & Prunus dulcis & 2 \\
\hline Castanea dentata & 3 & Pseudotsuga menziesi & 8 \\
\hline Castanea sativa & 1 & Quercus coccifera & 2 \\
\hline Catalpa bignonioides & 47 & Quercus rotundifolia & 1 \\
\hline Chamaecyparis lawson & 27 & Quercus rubra & 26 \\
\hline Cupressus arizonica & 2 & Salix babylonica & 5 \\
\hline Cupressus Iusitanica & 92 & Sambucus nigra & 1 \\
\hline Cupressus sempervire & 2 & Sem árvore & 24 \\
\hline Desconhecido & 9 & Sequoia sempervirens & 1 \\
\hline Fraxinus angustifoli & 11 & Tamarix gallica & 2 \\
\hline Ilex aquifolium & 4 & Thuja plicata & 3 \\
\hline Juniperus communis & 1 & Tilia tomentosa & 27 \\
\hline Ligustrum cinense & 15 & Viburnum prunifolium & 4 \\
\hline Melia azedarach & 4 & Total & 481 \\
\hline
\end{tabular}

A espacialização de todos os indivíduos arbóreos pode ser observada na Figura 3.

Oito espécies foram espacializadas individualmente. A seleção destas foi realizada utilizando o critério das mais recorrentes no campus. As espécies selecionadas foram: Acer negundo (Figura 4), Acer pseudoplatanus (Figura 5), Aesculus hippocastan (Figura 6), Catalpa bignioides (Figura 7), Cupressus lusitanica (Figura 8), Ligustrum cinense (Figura 9), Platanus hispanica (Figura 10) e Tilia tomentosa (Figura 11). 
Figura 3- Espacialização das árvores no Campus do Instituto Politécnico de Bragança, Santa Apolónia, Bragança, Portugal.

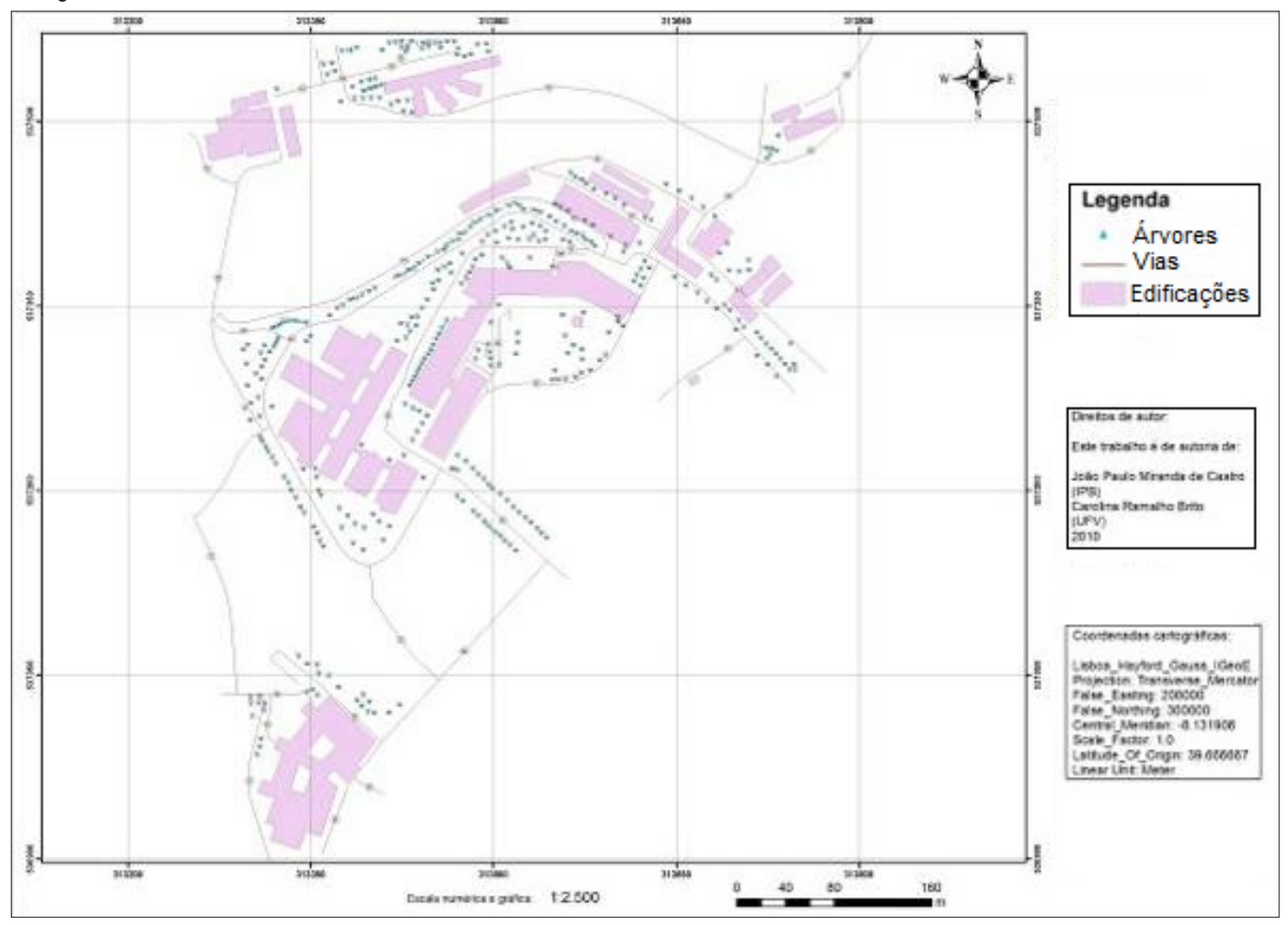

Figura 4- Espacialização da espécie Acer negundo no Campus do Instituto Politécnico de Bragança, Santa Apolónia, Bragança, Portugal

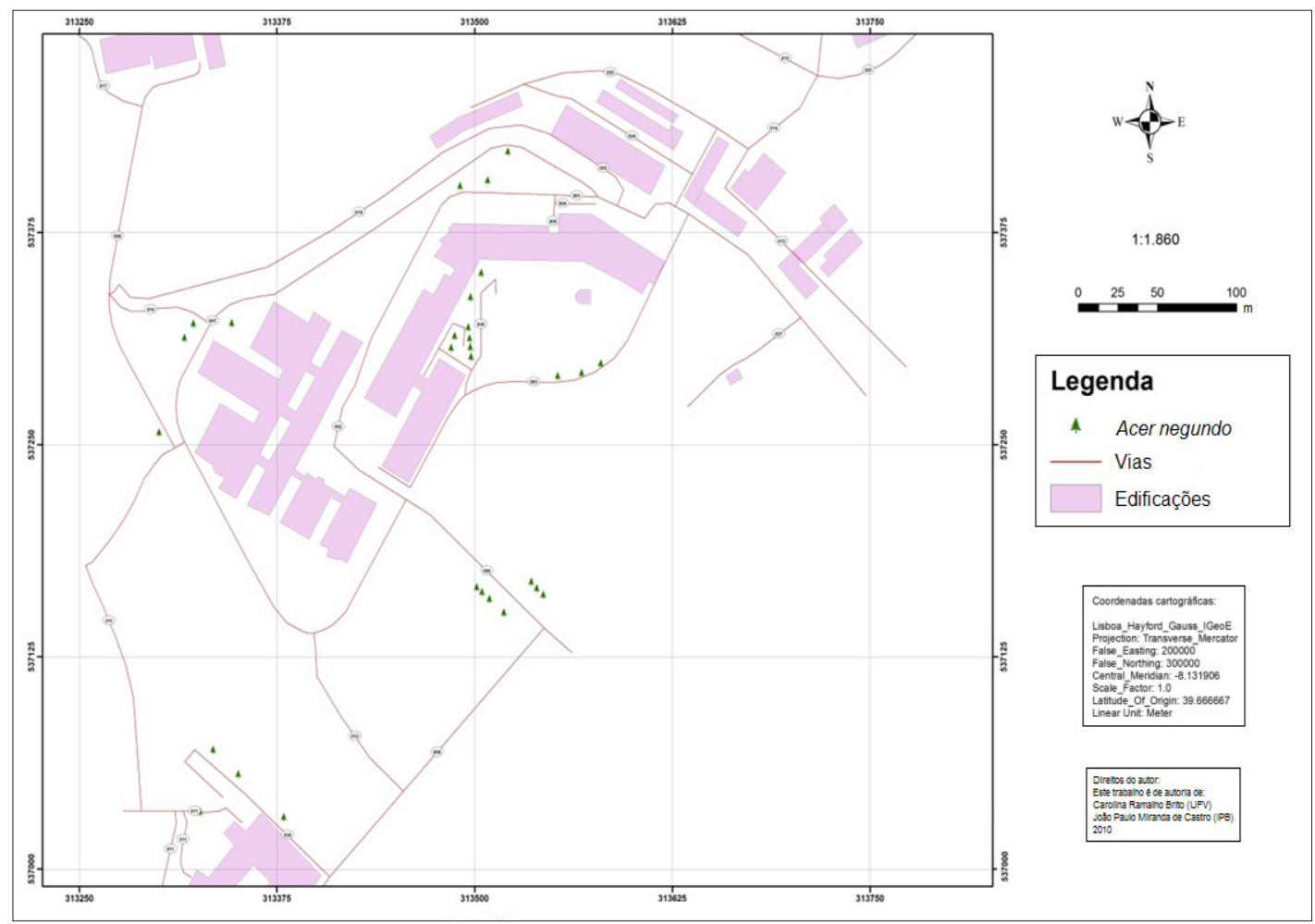

Geografia Ensino \& Pesquisa, v. 16, n.3 p. 157 - 178, set./dez. 2012

Brito, C.R.; Castro, J.P.M. de; Barros, K. O.; Faria, A.L.L. de. 
Figura 5- Espacialização da espécie Acer pseudoplatanus no Campus do Instituto Politécnico de Bragança, Santa Apolónia, Bragança, Portugal.

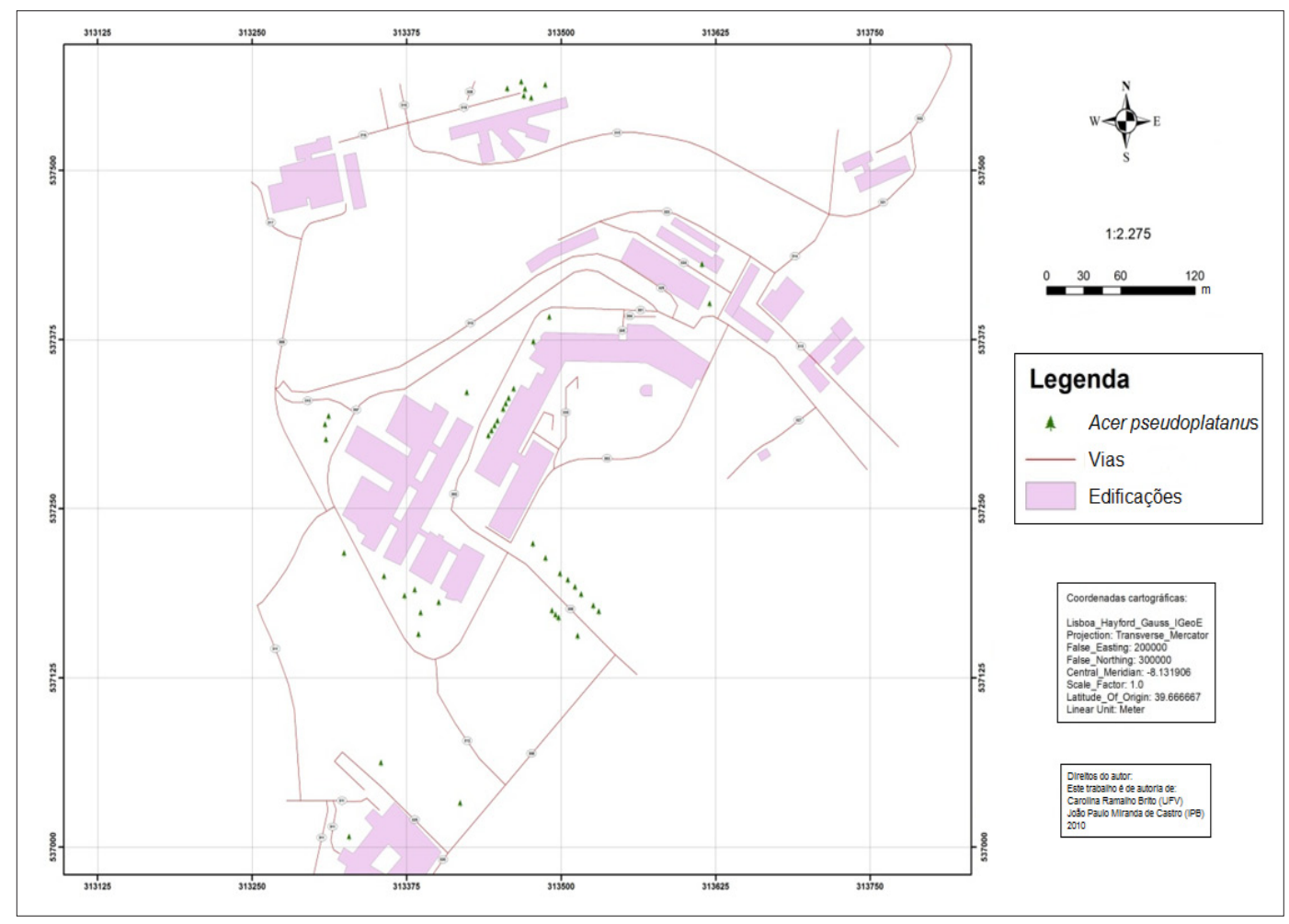

Figura 6- Espacialização da espécie Aesculus hippocastan no Campus do Instituto Politécnico de Bragança, Santa Apolónia, Bragança, Portugal.

Geografia Ensino \& Pesquisa, v. 16, n. 3 p. 157 - 178, set./dez. 2012

O uso de sig no inventário de árvores no Campus do Instituto Politécnico de Bragança, Portugal

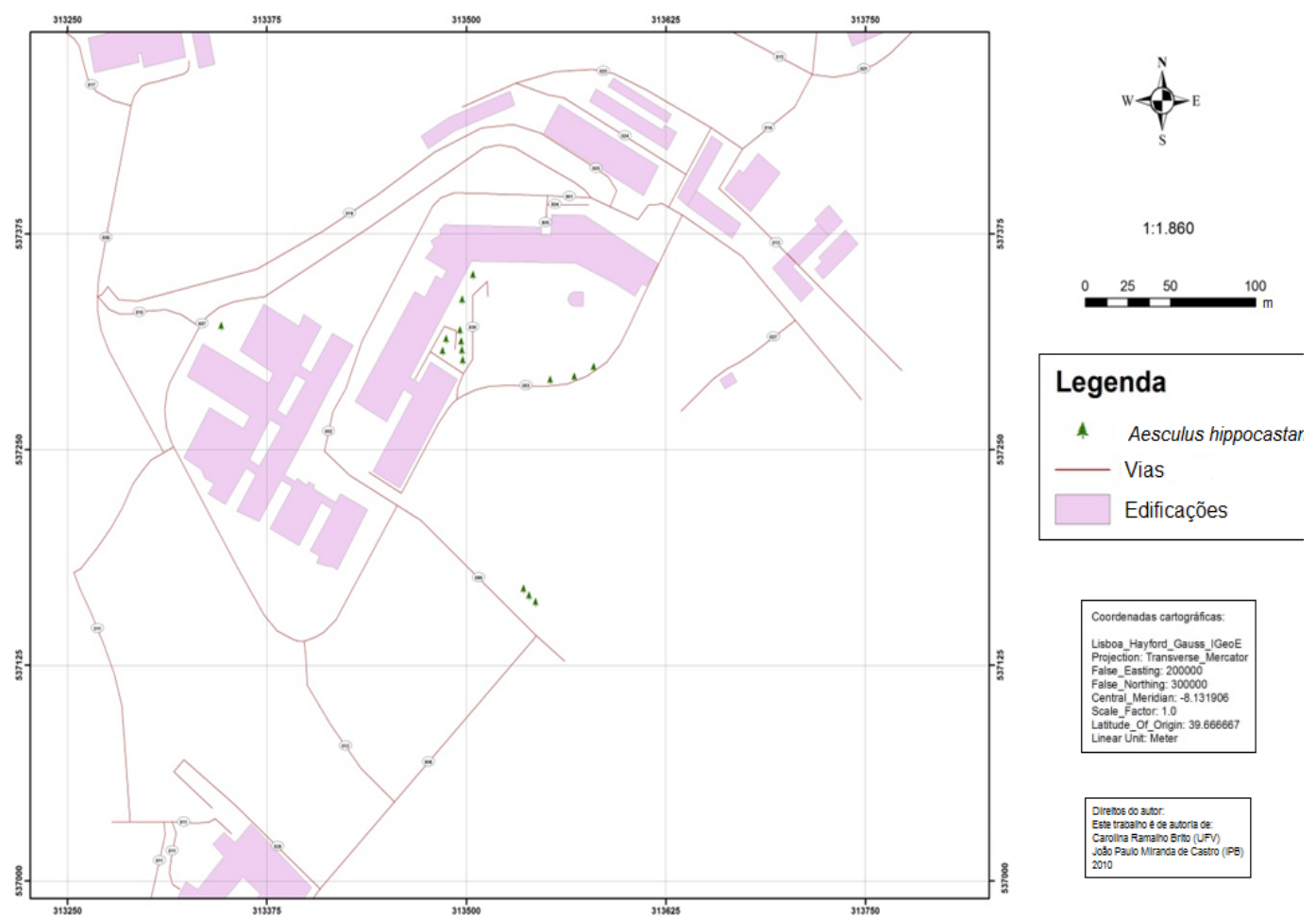




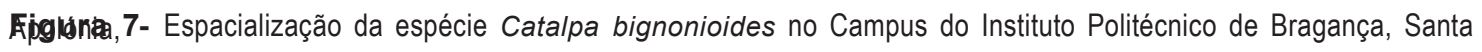
Bragança, Portugal.

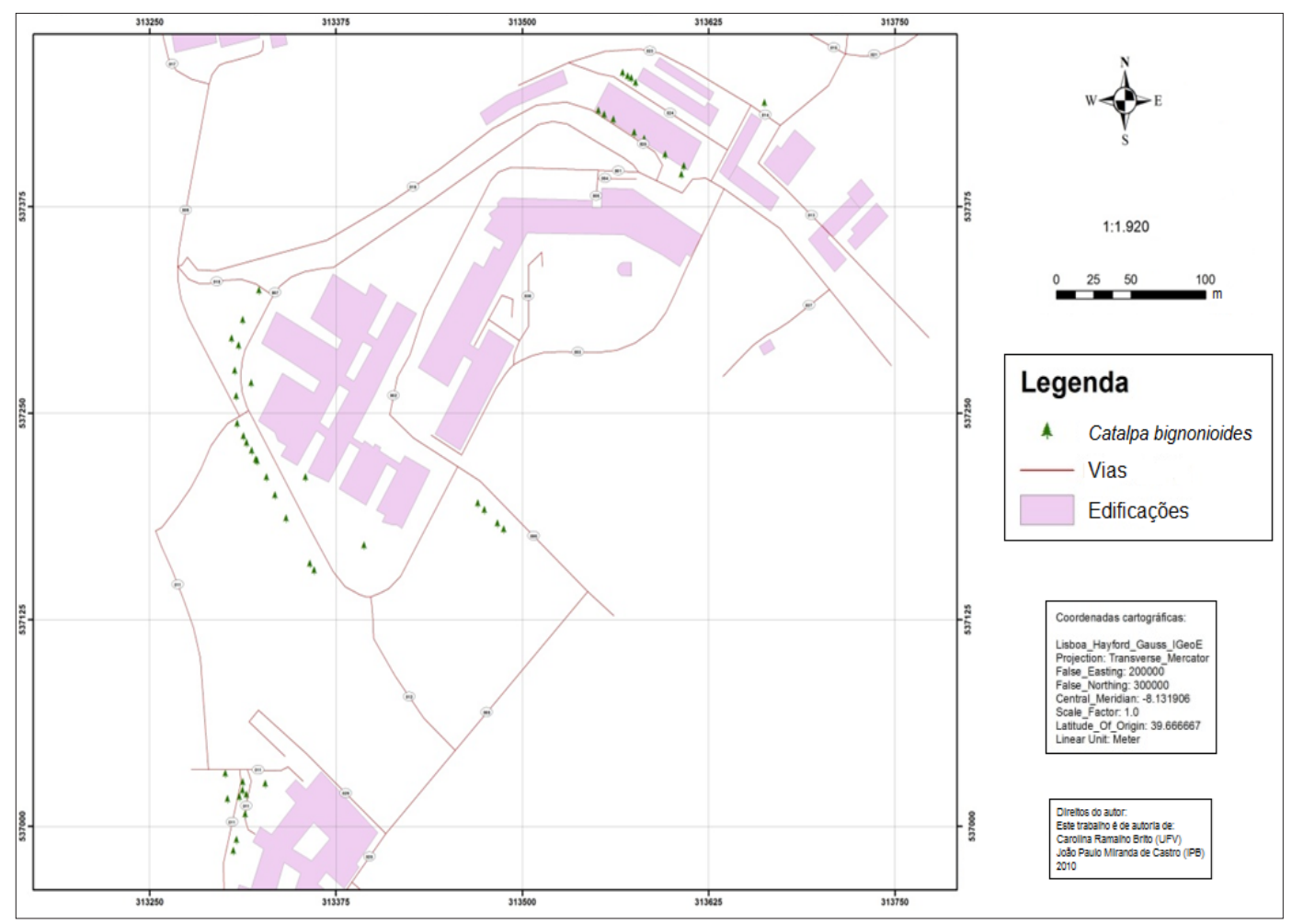

Figura 8- Espacialização da espécie Cupressus Iusitanica no Campus do Instituto Politécnico de Bragança, Santa Apolónia, Bragança, Portugal.

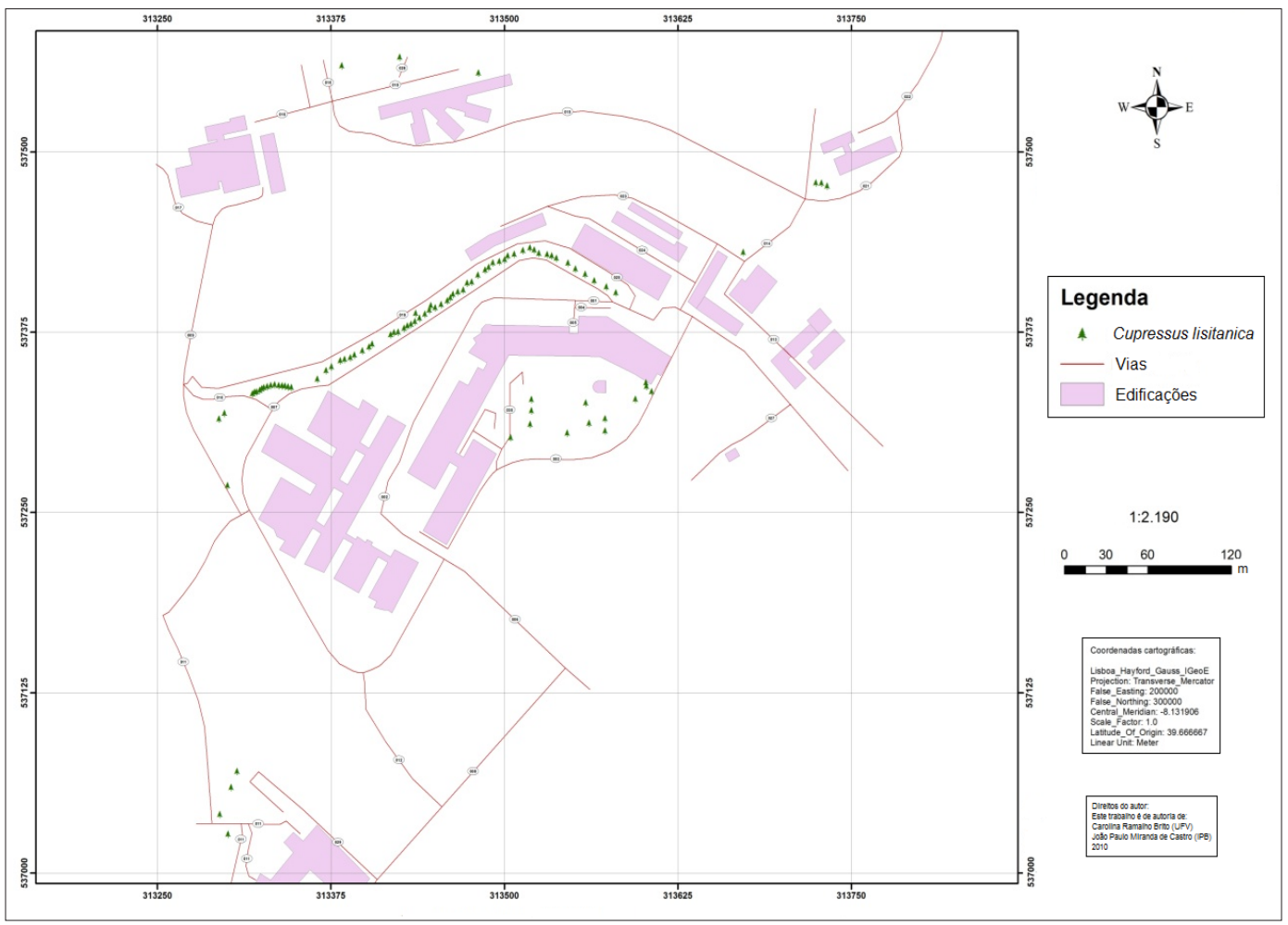

Geografia Ensino \& Pesquisa, v. 16, n.3 p. $157-178$, set./dez. 2012

Brito, C.R.; Castro, J.P.M. de; Barros, K. O.; Faria, A.L.L. de. 
Figura 9- Espacialização da espécie Ligustrum cinense no Campus do Instituto Politécnico de Bragança, Santa Apolónia, Bragança, Portugal.

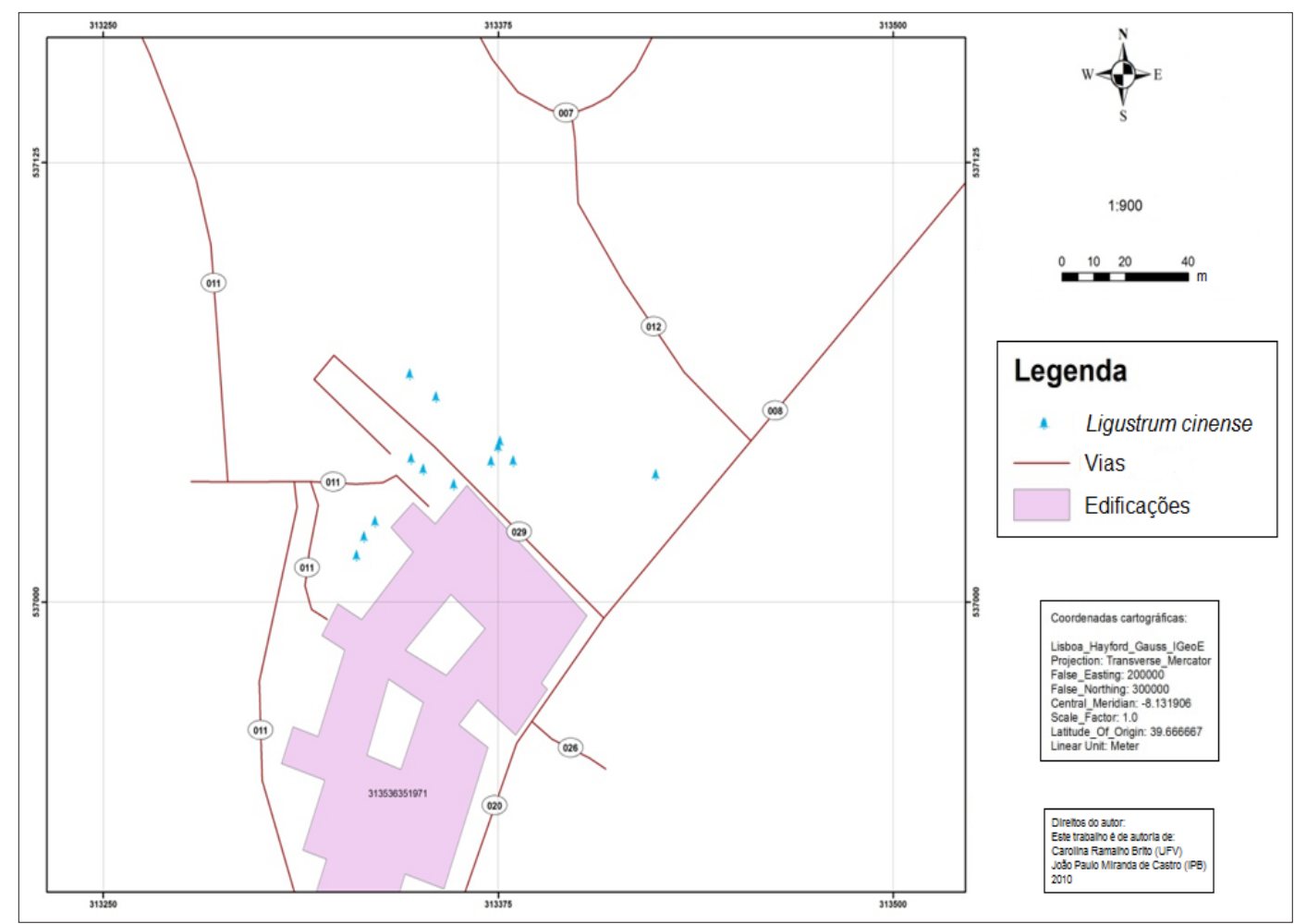

Figura 10 - Espacialização da espécie Platanus hispanica no Campus do Instituto Politécnico de Bragança, Santa Apolónia, Bragança, Portugal.

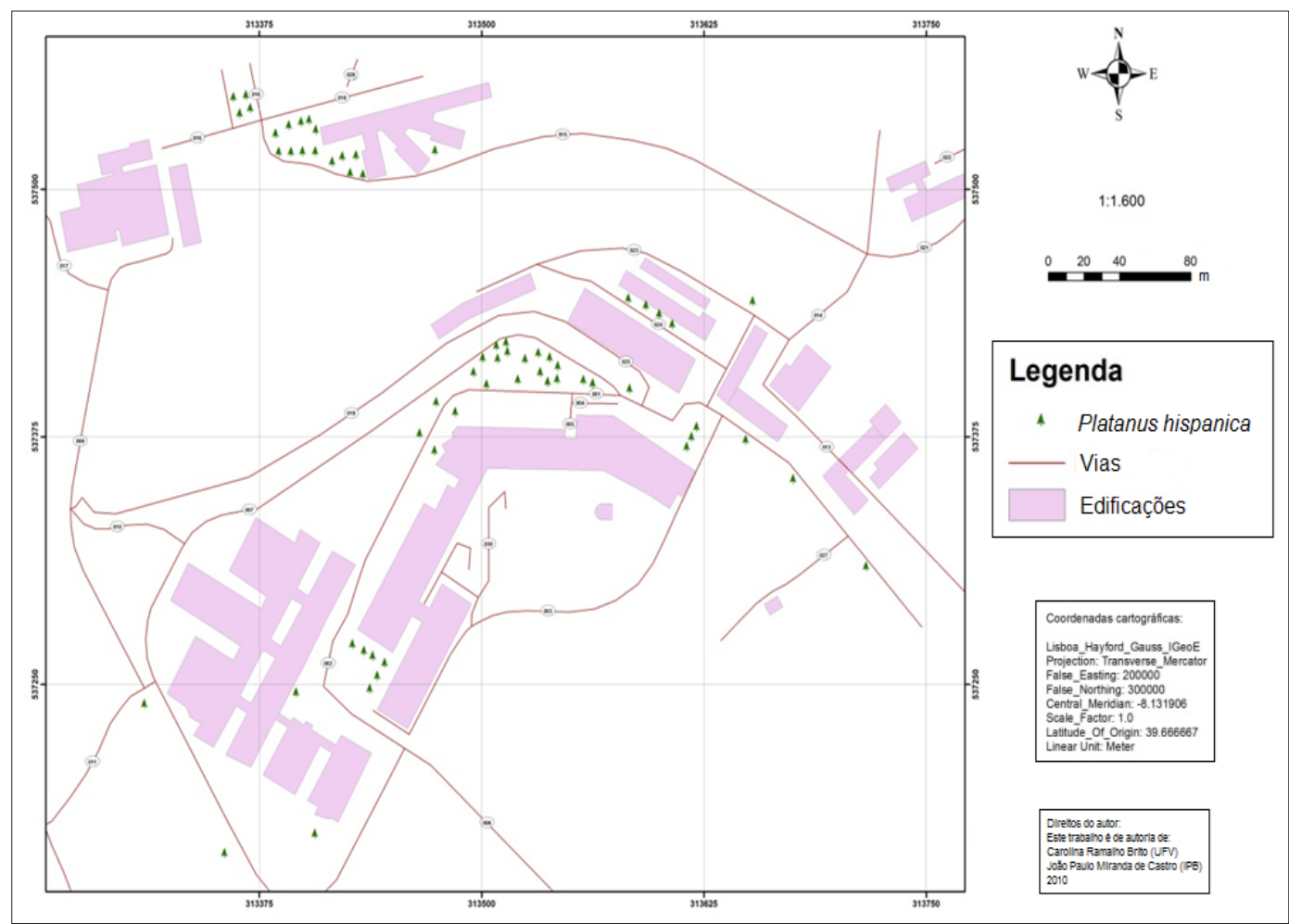

0 uso de sig no inventário de árvores no Campus do Instituto Politécnico de Bragança, Portugal 
Ájgldk再, 11- Espacialização da espécie Tilia tomentosa no Campus do Instituto Politécnico de Bragança, Santa Bragança, Portugal.

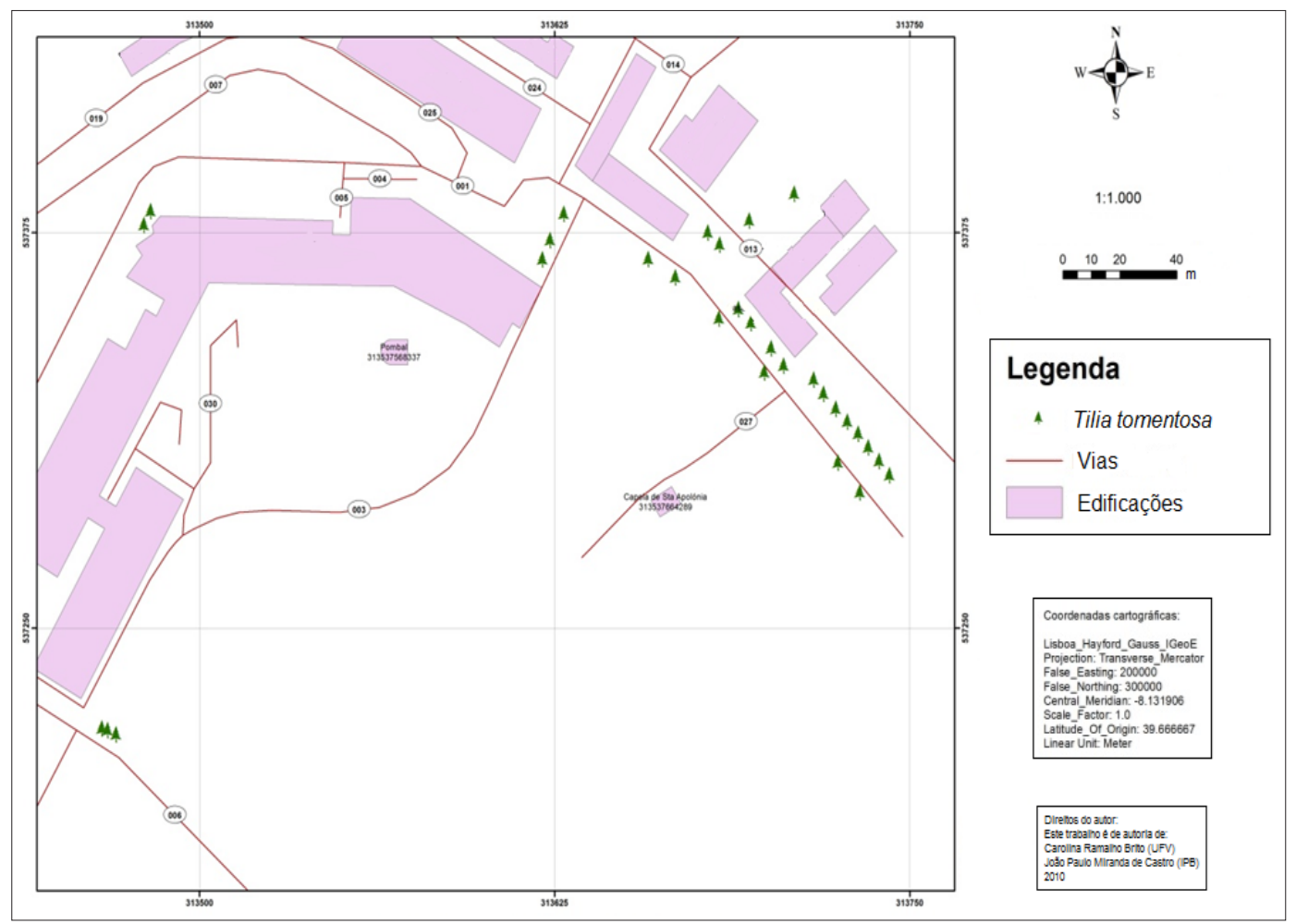

A espacialização dos indivíduos arbóreos (Figura 3) apontou que o campus contém principalmente árvores de alinhamento em Alameda ao longo das vias de comunicação. No entanto, pôde-se observar também árvores com Outro tipo de alinhamento ou em Bosquetes (agrupamento disperso) inseridas em jardins, árvores em Taludes não ajardinados e ainda cortinas de compartimentação.

Esta espacialização, especialmente a realizada por espécie, associada com as características e possíveis intervenções recomendadas, vem a facilitar a atuação do profissional responsável pela arborização da área de estudo. A identificação da localização exata do indivíduo assim como da medida a ser tomada torna-se muito mais eficiente com a associação da espacilização e demais informações sobre cada árvore. Além disso, a espacialização por si só contribui consideravelmente na posterior definição de novos plantios, já que é possível observar o atual arranjo dos indivíduos por espécies ou mesmo de maneira geral, possibilitando identificar áreas onde há maior necessidade de estabelecimento de plantios.

A diversificação das espécies utilizadas na arborização urbana deve considerada, no entanto, a localização de cada indivíduo deve ser planejada de modo que quesitos estéticos e paisagísticos sejam contemplados. É indicado que a uniformidade seja privilegiada dentro das ruas. Deve-se atentar também ao porte de cada espécie selecionada para que não ocorra problemas com fiações existentes. Vale ressaltar que cada local a ser arborizado tem características peculiares de de clima e solo. Neste sentido, a diversidade deve ser considerada, porém as espécies comuns à região devem utilizadas preferencialmente em relação às demais (DANTAS \& SOUZA, 2004).

No que diz respeito à Idade da árvore pode-se observar na Figura 12 que a maior parte dos indivíduos corresponde à idade Adulta, 50 \%, enquanto que $41 \%$ são Jovens e $2 \%$ correspondem a árvores Mortas presentes, mesmo valor dos indivíduos Senescentes. A classe Sem árvore apresentou o valor de $5 \%$.
Geografia Ensino \& Pesquisa, v. 16, n.3 p. 157 - 178, set./dez. 2012

Brito, C.R.; Castro, J.P.M. de; Barros, K. O.; Faria, A.L.L. de. 
Figura 12- Idade das espécies arbóreas no Campus do Instituto Politécnico de Bragança, Santa Apolónia, Bragança, Portugal.

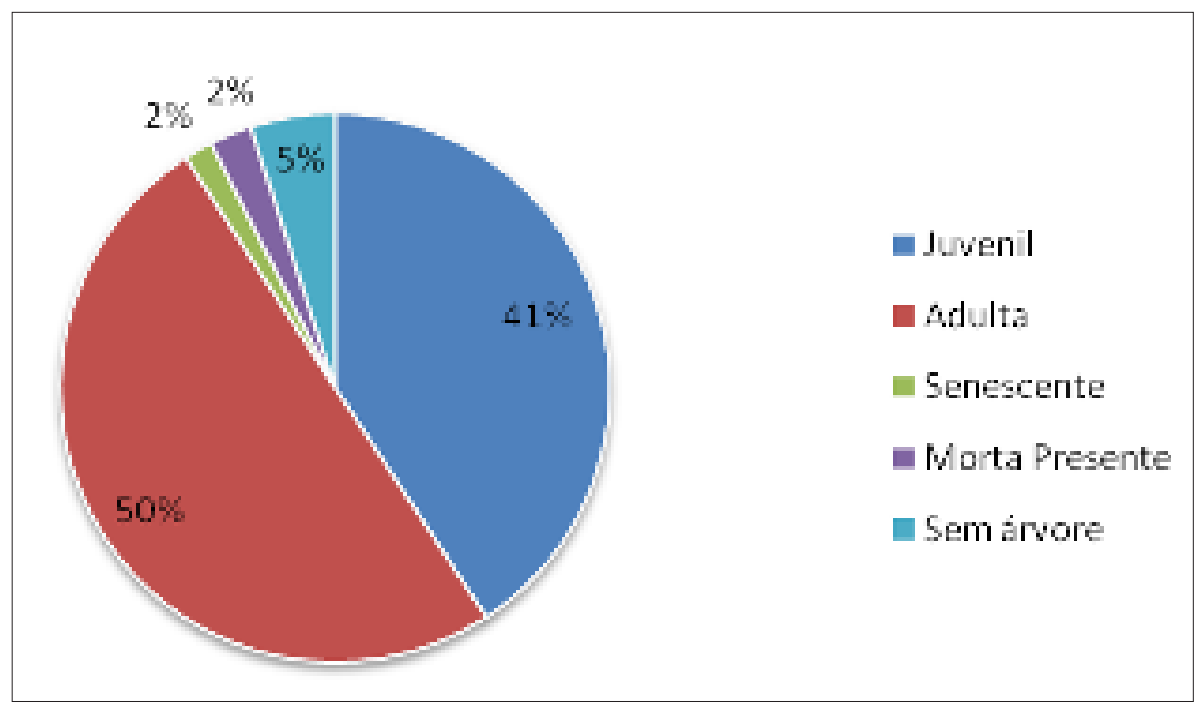

As médias dos parâmetros dendrométricos das principais espécies encontradas, sejam elas na forma adulta ou juvenil, podem ser observadas na Tabela 4.

Como foram encontradas algumas espécies que possuíam poucos exemplares no campus, foi calculado a média dos parâmetros dendométricos das principais espécies encontradas na forma adulta e juvenil.

$\mathrm{Na}$ Tabela 4 pode-se perceber qua as espécies Cupressus lusitanica e Platanus hispanica têm o maior diâmetro da base da copa, o que confere um bom sombreamento. Principalmente no caso da espécie Platanus hispanica, observa-se que, tanto na sua fase juvenil como na adulta, o diâmetro da base da copa foi o maior dentre as demais espécies. No que se refere à altura, estas duas espécies em questão foram aquelas que, na fase adulta, atingiram aproximadamente $12 \mathrm{~m}$, o maior nível dentre as demais. No campus em estudo, pode-se perceber que esta altura não causa interferência na fiação de energia elétrica. Neste sentido, tanto no que se refere à altura como ao diâmetro da base da copa, estas duas espécies podem ser consideradas adequadas para a realidade do campus. A boa adaptação destas espécies à região também deve ser considerada em sua seleção.

Tabela 4- Média dos parâmentros dendrométrico das principais espécies, na forma adulta e juvenil, encontradas no Campus do Instituto Politécnico de Brangaça, Santa Apolónia, Brangança, Portugal

Geografia Ensino \& Pesquisa, v. 16, n.3 p. 157 - 178, set./dez. 2012

0 uso de sig no inventário de árvores no Campus do Instituto Politécnico de Bragança, Portugal

\begin{tabular}{|c|c|c|c|c|c|c|c|c|}
\hline \multirow{2}{*}{$\begin{array}{l}\text { Parâmetros } \\
\text { Espécie }\end{array}$} & \multicolumn{2}{|c|}{ Média DAP } & \multicolumn{2}{|c|}{$\begin{array}{l}\text { Média } \\
\text { Altura }\end{array}$} & \multicolumn{2}{|c|}{$\begin{array}{l}\text { Média Altura Base } \\
\text { da Copa }\end{array}$} & \multicolumn{2}{|c|}{$\begin{array}{l}\text { Diâmetro da Base da } \\
\text { Copa }\end{array}$} \\
\hline & $\mathbf{J}$ & A & $\mathbf{J}$ & A & $\mathrm{J}$ & A & $\mathbf{J}$ & A \\
\hline Acer negundo & 2 & 20,5 & 1,9 & 7 & 1,15 & 1,96 & 1,5 & 5,25 \\
\hline Acer pseudoplatanus & 6,8 & 15 & 3,28 & 5,73 & 1,48 & 1,91 & 2,16 & 4,85 \\
\hline Aesculus hippocastan & 12,21 & - & 2,65 & - & 1,43 & - & 1,87 & - \\
\hline Catalpa bignonioides & 8 & 15,5 & 2,93 & 4,6 & 1,54 & 1,87 & 2,58 & 4,72 \\
\hline Chamaecyparis lawson & 7,3 & 27,3 & 6,46 & 0,9 & 0,67 & 2,6 & 1,58 & 3,8 \\
\hline Cupressus Iusitanica & 8,47 & 45,27 & 2,86 & 12,42 & 0,61 & 3,01 & 2,47 & 6,58 \\
\hline Ligustrum cinense & 2,6 & 30 & 1,25 & 4,5 & 0,46 & 1 & 0,75 & 5 \\
\hline Platanus hispanica & 10,62 & 39,12 & 6,68 & 12,03 & 1,95 & 2,58 & 4,93 & 8,57 \\
\hline Quercus rubra & 8,57 & 15,07 & 5,03 & 6,43 & 1,78 & 8,81 & 3,11 & 5,5 \\
\hline Tilia tomentosa & 12,83 & 19,86 & 5,2 & 7,03 & 10,07 & 8,65 & 4,47 & 5,9 \\
\hline
\end{tabular}

* $\mathrm{J}=$ Juvenil; $\mathrm{A}=$ Adulta. 
No entanto, ressalta-se que, para a espécie Cupressus lusitanica, Moser et al. (2010) apontou esta espécie como não indicada para a arborização urbana uma vez que, na avaliação da área de estudo após uma tempestade com forte ventos, esta foi uma das espécies mais danificadas, inclusive sendoa arrancadas pela raiz. Apesar de que, entre as espécie listadas na Tabela 4, a Cupressus lusitanica foi aquela que aprentou maior DAP na fase adulta, sua madeira é considerada fraca, com baixa resistência mecânica (MOSER et al., 2010).

As localizações das árvores podem ser observadas na Figura 13. Pôde-se perceber que a maioria delas encontra-se em talude junto à via, ou em jardim, ou ainda nos estacionamentos. Considerou-se que os indivíduos arbóreos estão bem localizados no Campus, já que privilegia o sombreamento de pedestres e veículos nos estacionamentos.

Figura 13- Localização das árvores no Campus do Instituto Politécnico de Bragança, Santa Apolónia, Bragança, Portugal.

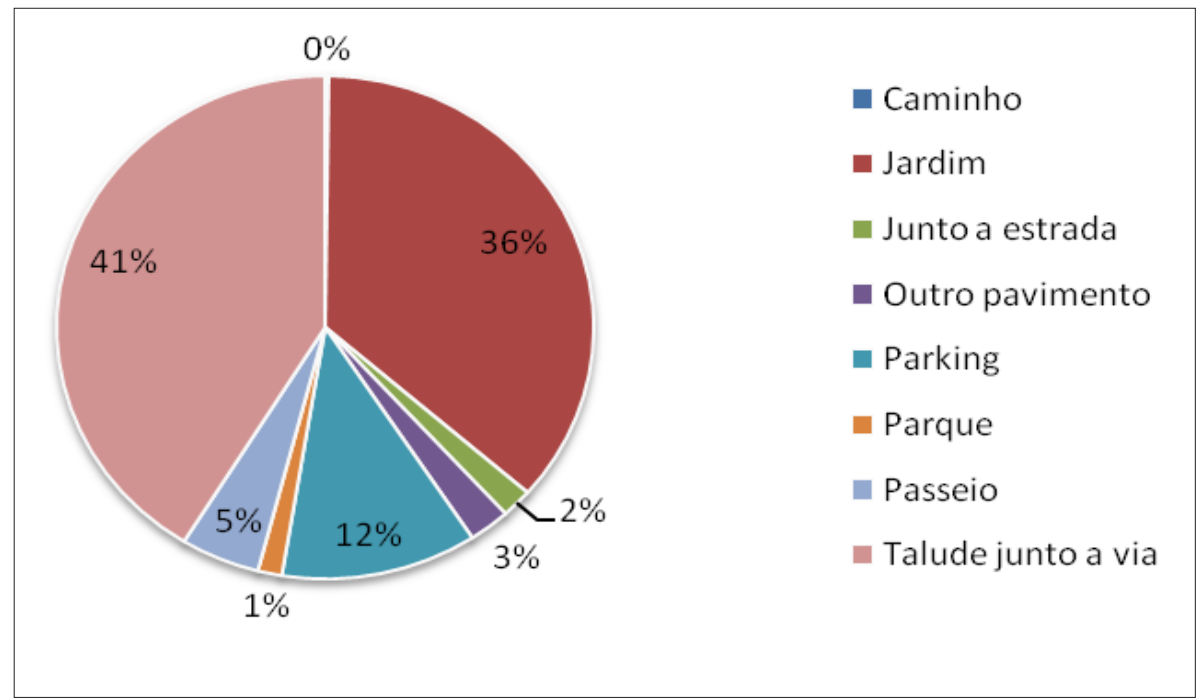

Em relação ao tipo de Associação (Figura 14), a maioria dos indivíduos arbóreos encontramse em Alameda de árvores ou em Outro alinhamento, sendo baixo o percentual de árvores que encontram-se isoladas no campus, $1 \%$.

Figura 14- Tipo de associação das árvores no Campus do Instituto Politécnico de Bragança, Santa Apolónia, Bragança, Portugal.

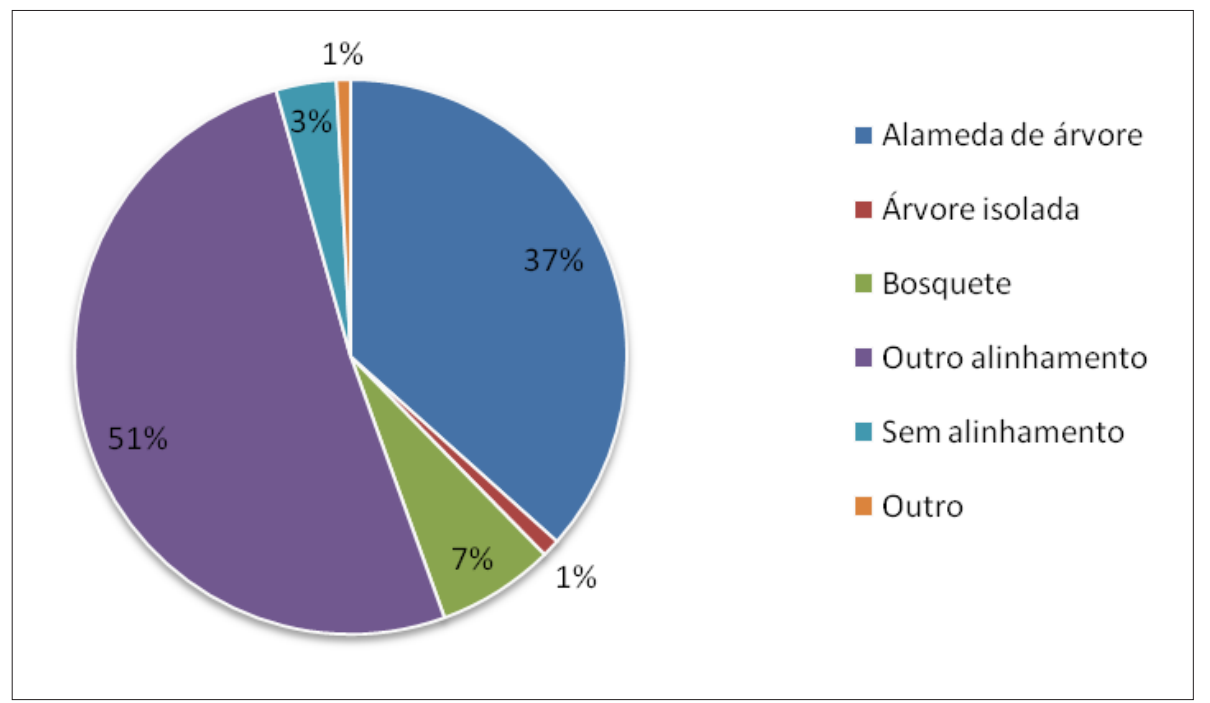

Geografia Ensino \& Pesquisa, v. 16, n.3 p. $157-178$, set./dez. 2012

Brito, C.R.; Castro, J.P.M. de; Barros, K. O.; Faria, A.L.L. de. 
O campus possui diferentes tipos de pavimentos, mas os que sobressaem são os pavimentos do tipo Ervado e Terra (Figura 15).

Figura 15- Tipo de pavimento das árvores no Campus do Instituto Politécnico de Bragança, Santa Apolónia, Bragança, Portugal.

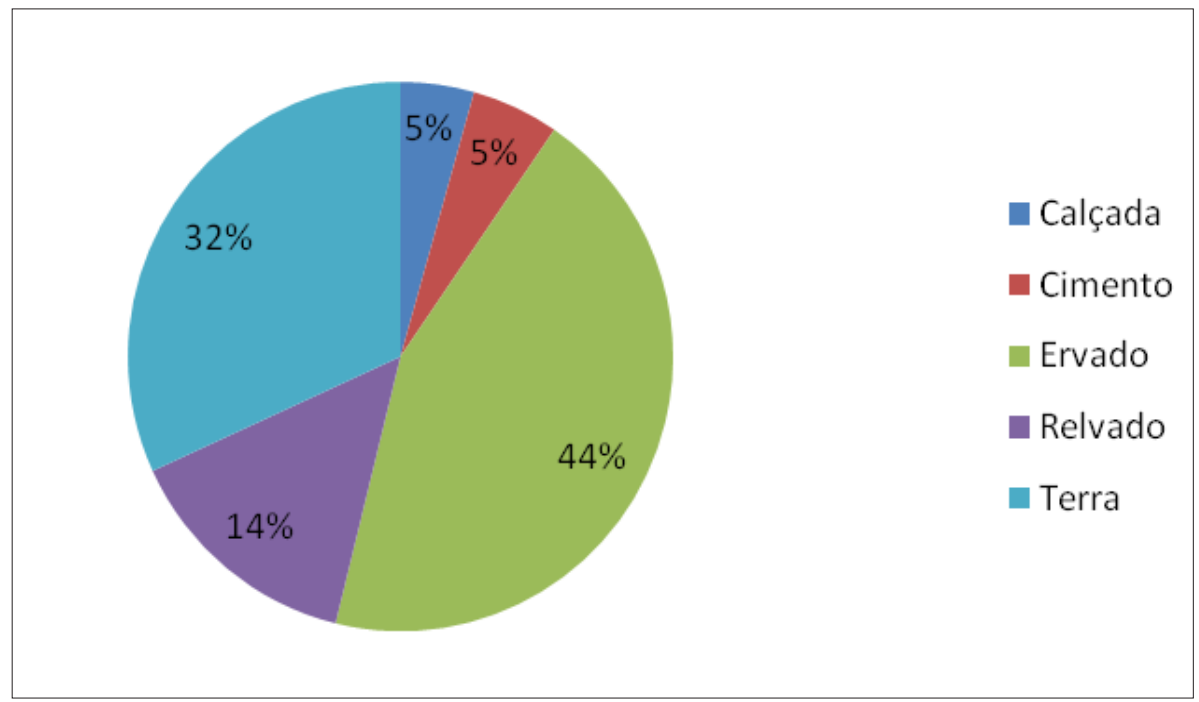

Os Fatores Limitantes da raiz encontrados foram poucos, a maioria não apresentou fatores limitantes. Dentre os fatores, aquele de maior destaque foi o Estacionamento, impedindo o crescimento da raiz. O principal Fator Limitante da copa também coincidiu com o da raiz, que é 0 Estacionamento, que, devido a presença constantes dos carros, as copas têm sempre seu tamanho limitado com a poda para que não atrapalhem os veículos. As dimensões das Caldeiras, mesmo que pouca utilizadas no campus, devem ser observadas, já que podem prejudicar o crescimento das raizes. Os Fatores limitantes da raiz, copa e global podem ser observados nas Figuras 16, 17 e 18 , nesta ordem.

Figura 16- Fatores limitantes da raiz para o crescimento das árvores no Campus do Instituto Politécnico de Bragança, Santa Apolónia, Bragança, Portugal.

Geografia Ensino \& Pesquisa, v. 16, n.3 p. 157 - 178, set./dez. 2012

O uso de sig no inventário de árvores no Campus do Instituto Politécnico de Bragança, Portugal

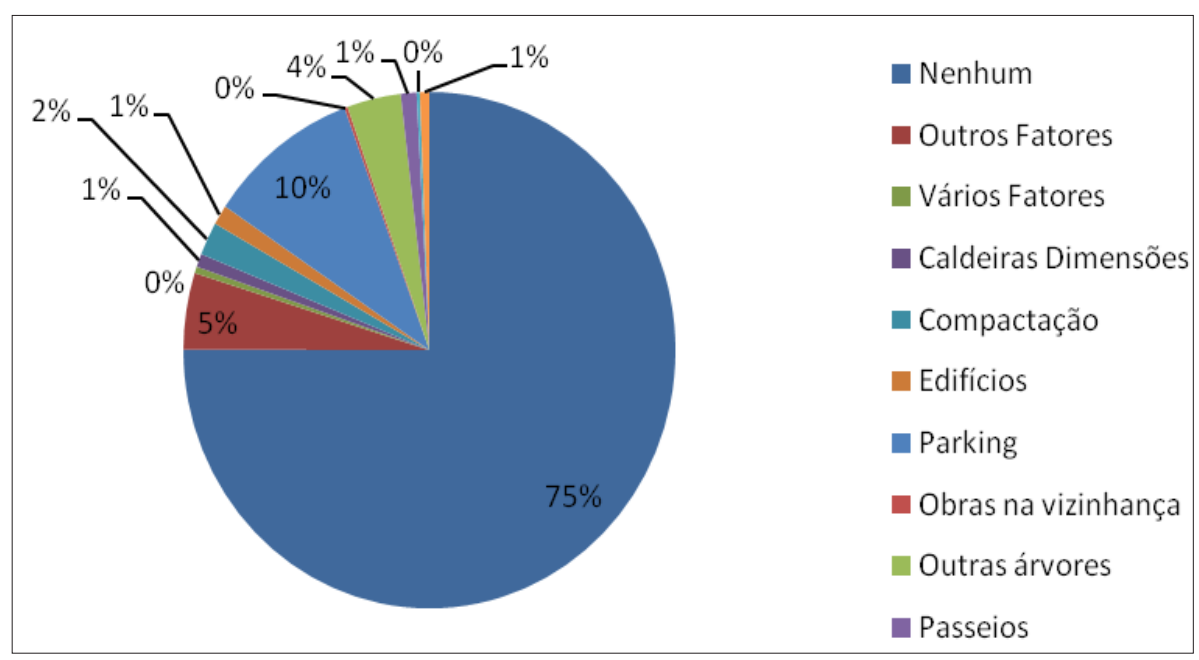


Figura 17- Fatores limitantes da copa para o crescimento das árvores no Campus do Instituto Politécnico de Bragança, Santa Apolónia, Bragança, Portugal.

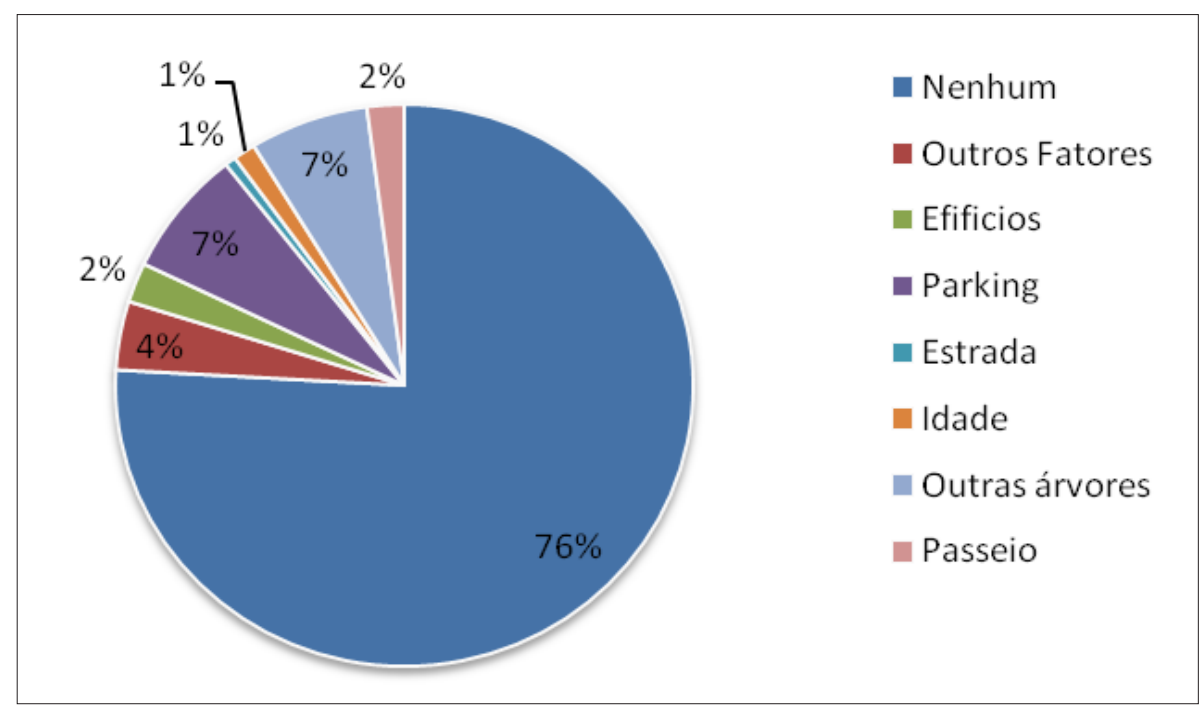

Figura 18- Fatores limitantes globais para o crescimento das árvores no Campus do Instituto Politécnico de Bragança, Santa Apolónia, Bragança, Portugal.

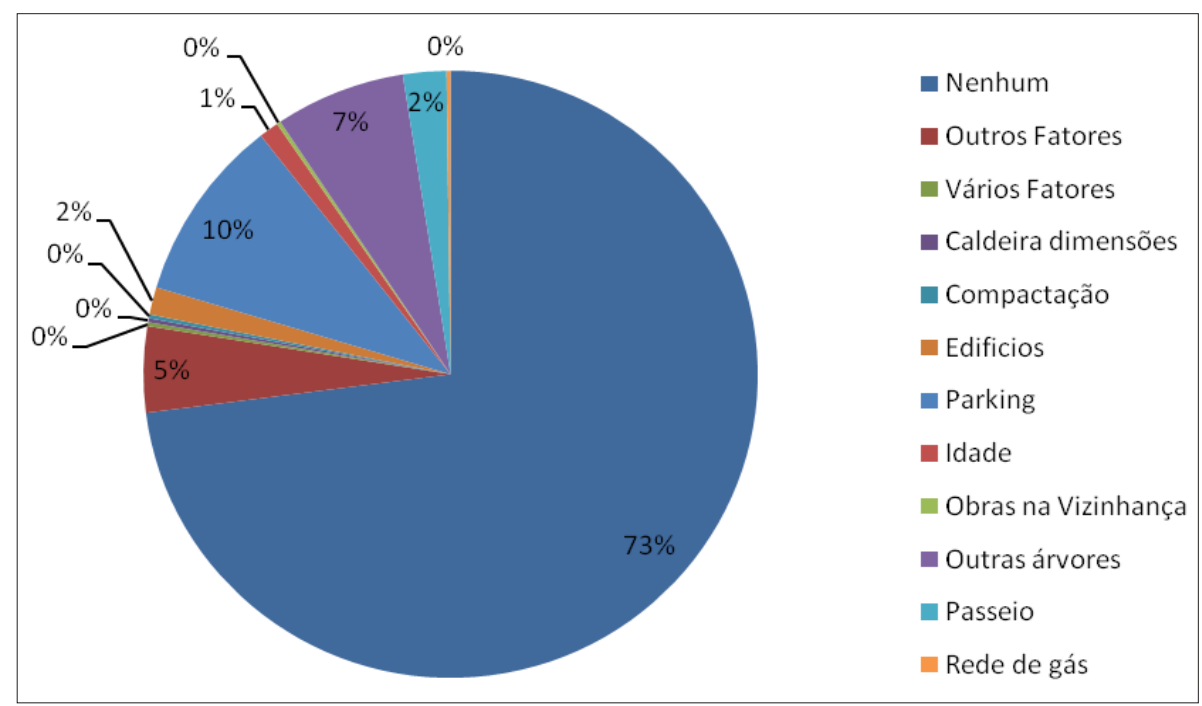

No que se refere à Sanidade dos indivíduos arbóreos pode-se observar que, de maneira geral, a boa saúde é uma característica da maior parte das árvores. Nas Figuras 19, 20 e 21 podem ser observadas, respectivamente, a Sanidade da raiz, ramos e tronco das árvores. 
Figura 19- Sanidade da raiz para as árvore do Campus do Instituto Politécnico de Bragança, Santa Apolónia, Bragança, Portugal.

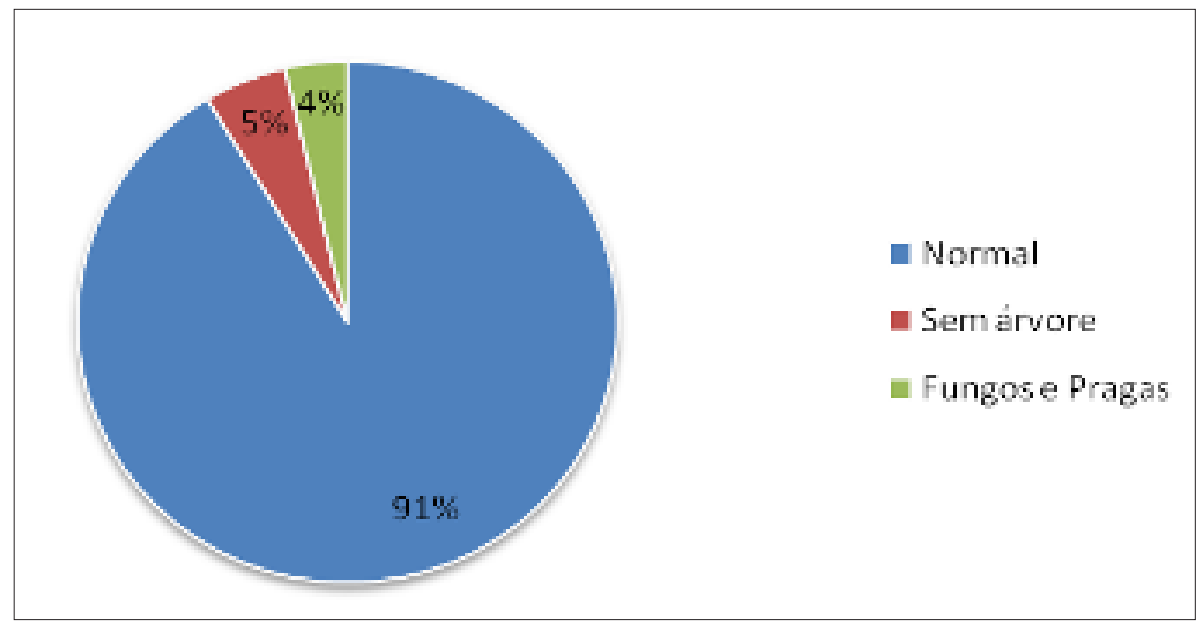

Figura 20- Sanidade dos ramos para as árvore do Campus do Instituto Politécnico de Bragança, Santa Apolónia, Bragança, Portugal.

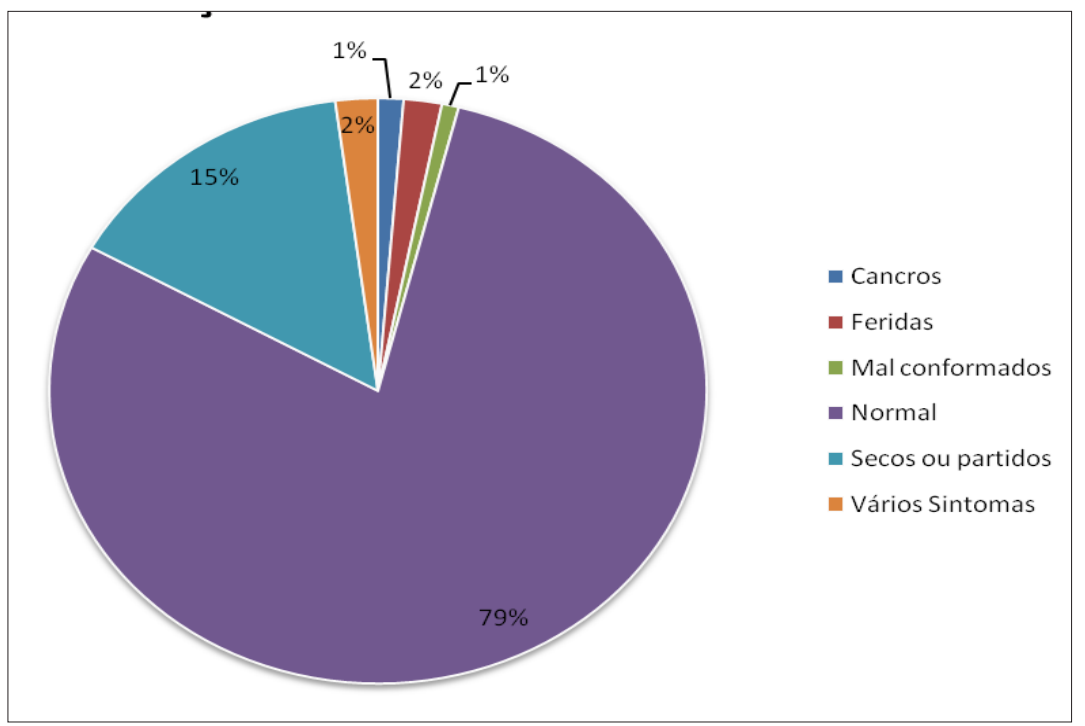

Figura 21- Sanidade do tronco para as árvore do Campus do Instituto Politécnico de Bragança, Santa Apolónia, Bragança, Portugal.

Geografia Ensino \& Pesquisa, v. 16, n. 3 p. 157 - 178, set./dez. 2012

O uso de sig no inventário de árvores no Campus do Instituto Politécnico de Bragança, Portugal

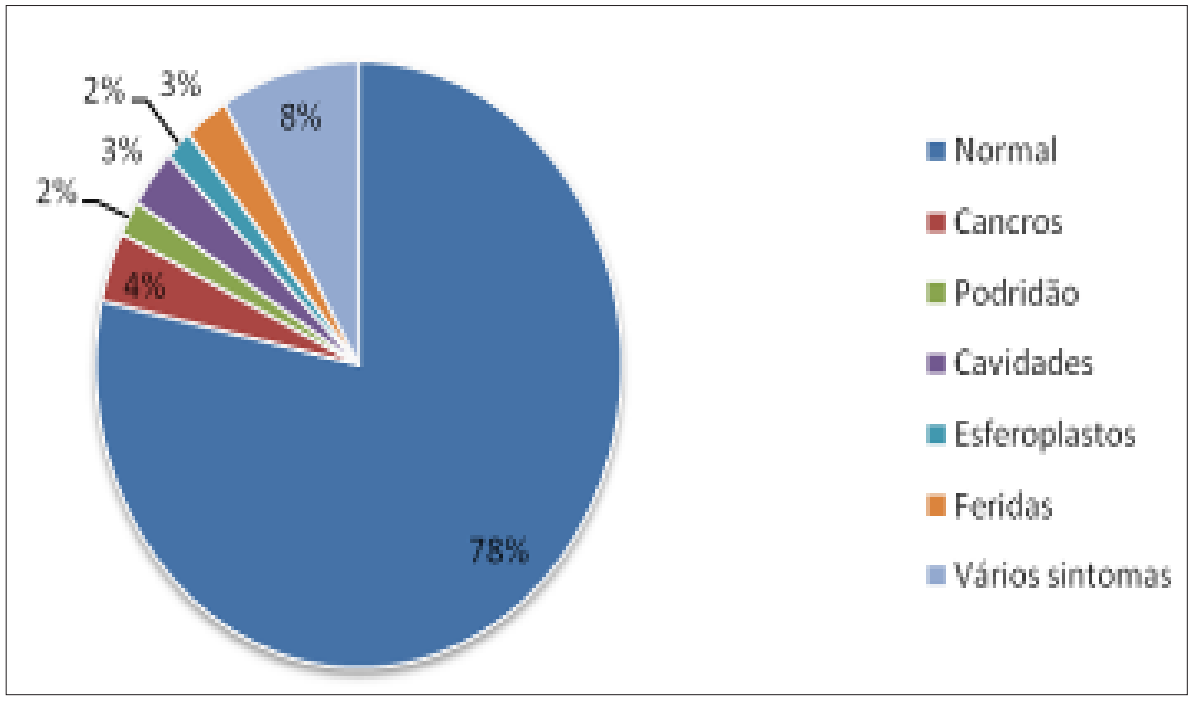


No que se refere ao parâmetro Irrigação, percebeu-se que nenhum indivíduo arbóreo é irrigado no campus. No entanto, os meses de junho, julho e agosto apresentam os menores índices pluviométricos com elevadas temperaturas, e, consequentemente, elevada evapotranspiração. Com estas características climáticas pode-se evitar um possível estress hídrico das plantas caso seja implantado algum sistema de irrigação.

As intervenções recomendadas podem ser observadas na Figura 22. Percebe-se que a maioria dos indivíduos não apresenta necessidade de qualquer intervenção. No entanto, as interferências porpostas variam desde a eliminação até o tratamento da árvore.

Figura 22- Intervenções recomendadas para os indivíduos arbóreos do Campus do Instituto Politécnico de Bragança, Santa Apolónia, Bragança, Portugal.

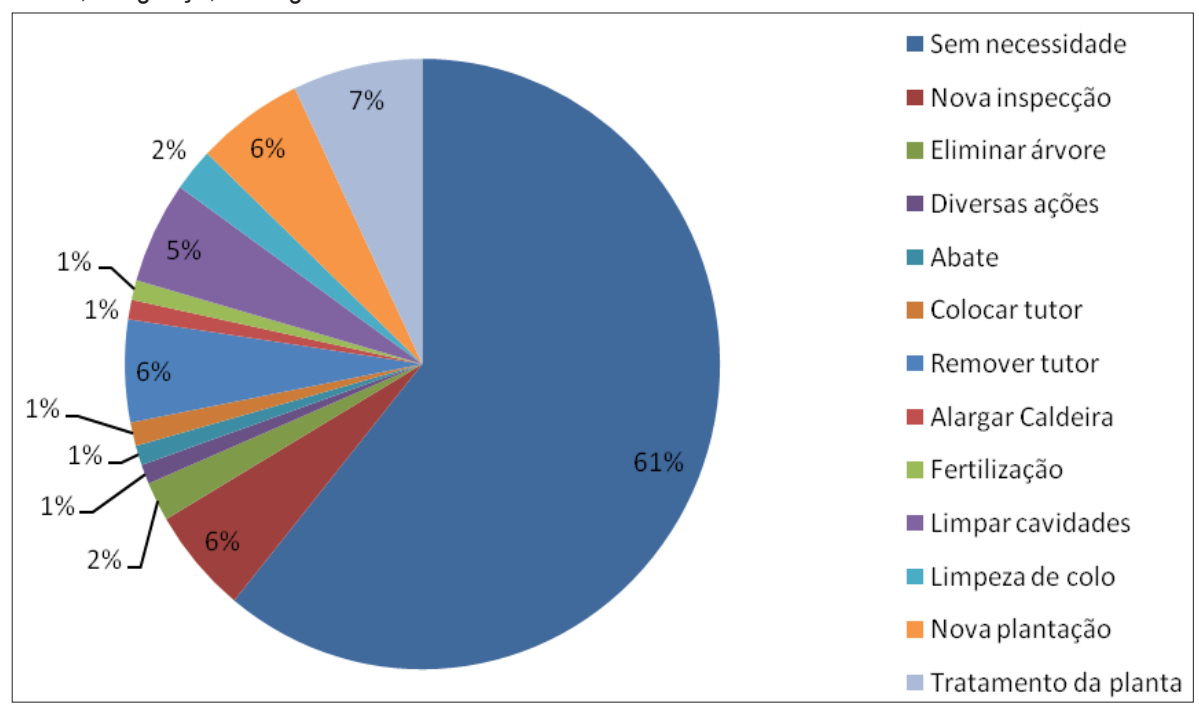

As espécies recomendadas para plantios futuros são - Platanus hispanica, Acer campestre, Catalpa bignonioides, Cumpressus lusitanica. Tais espécies foram escolhidas devido à excelente adaptação que têm na região.

A eliminação da árvore só foi indicada em casos extremos, no qual a árvore é Morta presente ou quando está causando perigo às pessoas. Constatou-se também a necessidade de demais intervenções como podas, tratamento da planta e fertilização para correção da deficiência nutricional. Esses problemas podem gerar consequências negativas para o meio ambiente e os animais que fazem parte do ciclo, além de interferir na beleza cênica no campus. A construção de caldeiras também é uma sugestão, já que, como mencionado, este suporte de proteção da raiz é encontrado em pequeno número no campus.

Recomenda-se também que uma nova inspeção da arborização do campus seja realizada em 2012, dois anos após esta avaliação.

De maneira geral, percebe-se que o estado geral das árvores é bom. Porém, algumas falhas foram detectadas no que tange à manutenção das árvores. Ainda assim, o patrimônio arbóreo tem muito potencial para evoluir favoravelmente e contribuir para o melhoramento da qualidade de vida das pessoas que frequentam o campus. Estas árvores contribuem para a biodiversidade, criando corredores ecológicos e abrigos em particular para aves. A curto prazo as vias pedestres de circulação e as zonas de estacionamento poderão se beneficiar ainda mais do sombreamento natural das copas das árvores.

Geografia Ensino \& Pesquisa, v. 16, n.3 p. 157 - 178, set./dez. 2012

Brito, C.R.; Castro, J.P.M. de; Barros, K. O.; Faria, A.L.L. de. 


\section{Conclusão}

A utilização dos Sistemas de Informações Geográficas foi uma ferramenta fundamental de suporte para o inventário urbano realizado. Com a espacialização das árvores e o conhecimento das características e das necessidades de cada indivíduo foi possível elaborar uma base de dados robusta que proporcionará uma maior facilidade no gerenciamento das atividades de arborização do campus do Instituto Politécnico de Bragança.

As caracterísitcas reveladas, tanto no que se refere à dendrometria dos indivíduos arbóreos como também à localização espacial deles e às intervenções recomendadas, percebe-se a necessidade de elaboração de um plano de arborização para a área do campus em estudo assim como de medidas relacionadas ao manejo deste.

\section{Agradecimentos}

À Universidade Federal de Viçosa por todo suporte durante a graduação.

Ao Instituto Politécnico de Bragança pela possibilidade de realização do intercâmbio.

\section{Referências Bibliográficas}

BERTRAND, G. Paisagem e geografia física global: esboço metodológico. Ra'e Ga, Curitiba, n. 8, p. 141-152, 2004.

CÂMARA MUNICIPAL DE BRAGANÇA. Disponível em: <http://www.cm-braganca.pt.> Acesso: 28 set. 2010.

CARVALHO, A. M.; GONÇALVES, A. Espaços Verdes de Bragança. Bragança: 2008.

CLARK, J.R. and MATHENY, N.P., 1993. Photographic Guide to the Evaluation of Hazard Trees in Urban Areas. International Society of Arboriculture. Second Edition. USA. ISBN: 9781881956044.

DANTAS, I. C.; SOUZA, C. M. C. Arborização urbana na cidade de Campina Grande - PB: inventário e suas espécies. Revista de Biologia e Ciência da Terra. v. 4, n. 2, 2004. Disponível em: <http://eduep.uepb.edu.br/rbct/sumarios/pdf/arborizaurba na.pdf> Acesso em: 13 ago. 2012.

INSTITUTO POLITÉCNICO DE BRAGANÇA (IPB). Disponível em: <http://www.ipb.pt.>. Acesso: 25 set. 2010.

LIMA NETO; E. BIONDE, D; ARAKI, H. Aplicação do SIG na arborização viária - Unidade Amostral em Curitiba- PR. III Simpósio Brasileiro de Ciências Geodésicas e Tecnologias da Geoinformação. Recife - PE, 27-30 de Julho de 2010.

LIMA NETO, E. M. de. Aplicação do sistema de informações geográficas para o inventário da arborização de ruas de Curitiba, Dissertação. Universidade Federal do

Geografia Ensino \& Pesquisa, v. 16, n.3 p. 157 - 178, set./dez. 2012

O uso de sig no inventário de árvores no Campus do Instituto Politécnico de Bragança, Portugal
Paraná em 2011.

MAGRO, T. C. Manejo de paisagens em áreas florestadas. Silvicultura, v. 18, n. 69, p. 38-45, 1997.

MARTINS, T.; RIBEIRO, J.L.P. \& GARRETT, C. Estudo de validação do questionário de avaliação da sobrecarga para cuidadores informais. Psicologia, Saúde \& Doenças, Vol. 4, 1, pp. 131148. 2003. 
MENEGUETTI, G. I. P. Estudo de dois métodos de amostragem para inventário da arborização de ruas dos bairros da orla marítima do município de Santos - SP. Dissertação (Mestrado em Recursos Florestais). Piracicaba: ESALQ/USP - Escola Superior de Agricultura "Luiz de Queiroz", 2003.

MOSER, P.; SILVA, A. C.; HIGUCHI, P.; SANTOS, E. M.; SCHMITZ, V. Avaliação pós-tempestade da arborização do campus da Universidade do Estado de Santa Catarina, Lages - SC. REVSBAU, v. 5, n. 2, p. 40-51, 2010. Disponível em: <http:// www.revsbau.esalq.usp.br/artigos_cientificos/ artigo133-publicacao.pdf> Acesso em: 13 ago. 2012.

PIVETTA, K. F. L. SILVA FILHO, D. F. da. Arborização Urbana. BOLETIM ACADÊMICO Série Arborização Urbana UNESP/FCAV/FUNEP Jaboticabal, SP - 2002. Disponível em: http:// www.slideshare.net/flavia.smarti/arborizao-urbana. Acesso: 17 ago. 2010.

RODRIGUES, L. M. T. 2008a. Avaliação da condição actual e valor patrimonial das árvores de interesse público dos distritos de Vila Real, Viseu e Bragança. Rel. Final Est. Eng. Flor., UTAD, Vila Real, 61 pp.

RODRIGUES, L. M. T. 2008b. Condição Actual e Valor Patrimonial das Árvores de Interesse Público. Debate: As Árvores: do meio urbano à floresta. UTAD. Vila Real.

SARMIENTO, M. Á; RODRÍGUEZ, A. P. Métodos de valoración ambiental: un nuevo método basado en la variación del Producto Interior Bruto. Catastro. 2005. Disponível em: http://www.catastro.meh.es/esp/publicaciones/ct/ct53/03-CATASTRO _53.pdf. Acesso: 20 set. 2010.

TRIMBLE, Navigation Limited. Manual Técnico das Especificações do receptor Juno Handheld. SB, 2007.

VITÓRIA, E. S. S. et al. Inventário da arborização do bairro Jardim Canaã do município de Monte Alto, SP. In: Congresso Brasileiro de Arborização Urbana, 14. Bento Gonçalves, 2010. Anais... Bento Gonçalves-RS, 2010.

\section{Correspondência:}

Carolina Ramalho Brito - Universidade Federal de Viçosa, Conselho Universitário. Av. PH Rolfs, s/n. Centro. 36570-000 - Vicosa, MG - Brasil

E-mail: carolrambri@hotmail.com

Recebido em 07 de setembro de 2011.

Revisado pelo autor em 19 de julho de 2012.

Aceito para publicação em 22 de outubro de 2012.

Geografia Ensino \& Pesquisa, v. 16, n.3 p. 157 - 178, set./dez. 2012 